\title{
A conglomeration of preclinical models related to myocardial infarction
}

\author{
Farogh Ahsan $^{1}$, Tarique Mahmood ${ }^{\oplus}$ *, Shazia Usmani ${ }^{1}$, Paramdeep Bagga $^{1}$, Arshiya Shamim $^{1}$, \\ Reshu Tiwari ${ }^{1}$, Neeraj Verma ${ }^{2}$, Mohammed Haris Siddiqui ${ }^{3}$ \\ ${ }^{1}$ Faculty of Pharmacy, Integral University, Lucknow, U.P., India, ${ }^{2}$ Department of Pharmacology, Hygia Institute of \\ Pharmaceutical Education and Research, Lucknow, U.P., India, ${ }^{3}$ Department of Bioengineering, Integral University, Lucknow, \\ U.P., India
}

\begin{abstract}
Cardiovascular diseases are the main source of death and morbidity in developed and developing nations. Animal models are required to propel our understanding of the pathogenesis, increase our knowledge, disease progress, and mechanism behind cardiovascular disorder, providing new approaches focused to improve the diagnostic and the treatment of these pathological conditions and additionally to test various therapeutic ways to deal with tissue regeneration and re-establish heart working following damage. A perfect model framework ought to be reasonable, effectively controlled, reproducible, and physiologically illustrative of human disease, show cardinal signs and pathology that resembles after the human ailment and ethically stable. The decision of selection of animal model should be considered precisely since it influences exploratory results and whether results of the research can be sensibly matched with the human. In this way, no specific technique splendidly reproduces the human disease, and relying upon the model, extra cost burden, resources, infrastructure and the necessity for technical hands, should also be kept under consideration. Here we have discussed and compiled various methods of inducing myocardial infarction in animals, basically by surgery, chemicals and through genetic modification, this may benefit the researchers in getting a complied data regarding various methods through which they can induce myocardial infarction in animals.
\end{abstract}

Keywords: Myocardial infarction. Animal model. Isoproterenol. Chemical induced. Ischeamia.

\section{INTRODUCTION}

Cardiovascular diseases are the most common and leading cause of morbidity and mortality across the world. CVD is a broad term which includes hypertension, coronary heart disease, congestive heart failure, and stroke. CVDs account 17.3 million deaths per annum globally (Reeve et al., 2005). Among all CVDs, Myocardial infarction (MI) is responsible for $10 \%$ of the total mortality (Alexander, Bruneau, 2010). In order to prevent and treat CHF more effectively, it is quite necessary to understand the pathophysiological mechanisms behind this disorder. Therefore, in vivo models closely related to the structural and functional characteristics of human CHF are used for analysis. However, to study all aspects of CHF a single model can't be used as every animal model has some pros and cons. when an animal model is being established

*Correspondence: T. Mahmood. Faculty of Pharmacy, Integral University, Lucknow, India. E-mail: tmahmood@iul.ac.in some technical points are to be considered such as model, species, strain and gender affecting the pathophysiology of the malfunctioning heart. The therapeutic objectives for the treatment of HF are focused on improving the patient's quality of life, alleviating or reducing symptoms, preventing hospitalisation, slowing the progression of the illness and increasing the survival rate (Oliveira et al., 2013).

The use of animals with medical and biological objectives has been practiced for centuries and this practice has added to our understanding and providing new methodologies focused to advance the diagnostic and treatment of certain pathologies. Areas of biomedical research, such as pharmacology, physiology, and toxicology, have based their progress in experiments carried out mainly in animal models or in the accurate observations of spontaneous phenomena in animals. The results obtained in animal models provide invaluable information for the design of tests for new pharmacological products in human beings. 
The test of a new product in human beings must begin by experimenting on intact animals; this is apart from the tests in other models, such as cell culture. The improvement of animal models of cardiovascular disease (CVD), including heart and athero thrombotic problem, has furnished us today with vital experiences into the pathophysiology, and they were observed to be basic apparatuses to assess new remedial methodologies for their earlier prediction and to inhibit these complications (Chandrasekera, Pippin, 2015). Endothelial dysfunction is one of the main underlying pathophysiological alterations in cardiovascular disorders like hypertension, coronary artery disease and heart failure (Páez et al., 2013). Coronary artery ligation is a most commonly utilized model of causing myocardial infarction for identification of drugs, cells or proteins. In this system, scientist stated that initially a thoracotomy is performed on the anesthetized animal, and the heart is quickly exteriorized by applying little pressure on the right side of the chest cavity. The coronary vein is either ligated or occluded up between the pulmonary artery outpouring tract and the left ventricle. The heart is then placed back to its ordinary position and the thorax is promptly closed (Zaragoza et al., 2011).

There are two principle ligation models, left anterior descending artery (LAD) ligation to instigate a myocardial infarction (MI) and a brief coronary artery impediment to incite ischemia/reperfusion damage (IR) (Gao et al., 2011). Obviously one disadvantage is that animals have dissimilar physiologies when compared to human (Halapas et al., 2008) so as scientist we should think about this. However there are a few advantages to this model method, for example, undamaged pectoral muscles, which is huge in light of the fact that these muscles are basic to cover the opening once the heart has been come back to the thoracic cavity and restrain the sewing of the muscle. Aside from surgical strategies MI can be prompted by different chemicals, for example, catecholamines, cytotoxic medications particularly anthracyclines. Quality knockout animal models have ended up being an essential segment in conjunction with transgenic lines of mice as a method for producing "human similar" mouse models as a component of new drug discovery systems (Klocke et al., 2007).

Here, we have summarized the various common methods for induction of Myocardial infarction, including those implemented in both large and small animals, designed for helping to cover with more precision and to better understand every single aspect related to these human pathologies.

\section{Methods of induction of myocardial infarction}

There are various methods for induction of Myocardial Infarction both via In vitro and in vivo methods. An accurate MI model should be beneficial for an accurate targeting of the various parameters (Figure 1).

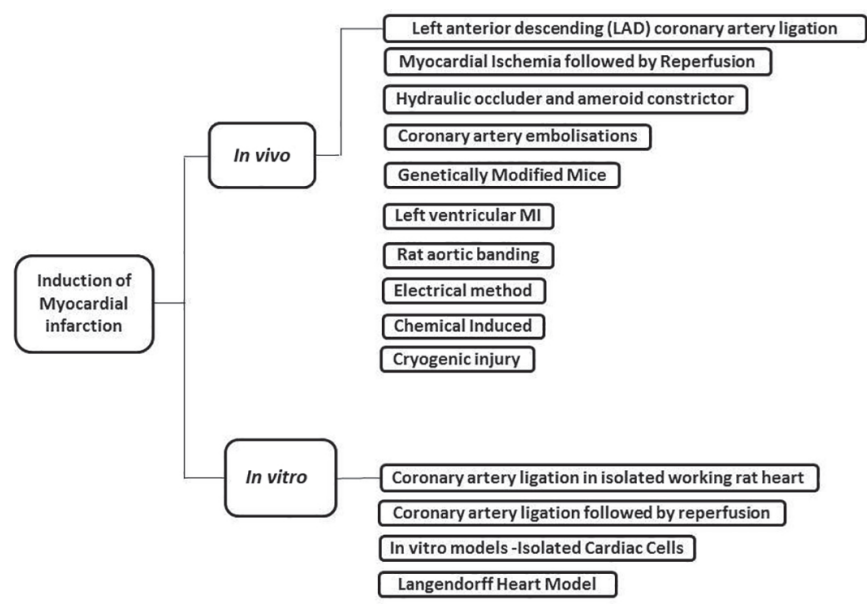

FIGURE 1 - Various methods for Induction of Myocardial Infarction

\section{In vitro}

Coronary artery ligation in isolated working rat heart Coronary artery ligation followed by reperfusion Langendorff Heart Model

In vitro models -Isolated Cardiac Cells

\section{In vivo}

\section{Left anterior descending (LAD) coronary artery ligation}

Left ventricular MI

Myocardial Ischaemia followed by Reperfusion

- Coronary artery ligation followed by reperfusion

- Minimal Invasive Ischaemia/Reperfusion Model

- Ischaemia/Reperfusion with Ischaemic Preconditioning

Electrical method

Coronary artery embolisations

Hydraulic occluder and ameroid constrictor

Rat aortic banding

Cryogenic injury

Genetically Modified Mice

a) Knockout Mouse Model:

i. LDLR-/- Mice

ii. ApoE-/- Mice

b) Transgenic Mice

Chemical Induced 


\section{In vitro \\ Coronary artery ligation in isolated working rat heart}

In functioning heart arrangement of rats, ischemia can be caused by tying the left coronary artery starting at its origin. After the clip has been removed, differences in the reperfusion period can be clearly seen. Measures taken to prevent these symptoms can be used to define efficacy of cardiac drugs (Vogel, 2007).

Wistar rats weighing 280-300 g of either sex are sacrificed by decapitation. The hearts are removed and made free from surrounding connective tissue and epicardium. A cannula is inserted in the aorta according to the Langendorff technique from where the coronary vessels are perfused along the nonrecirculated perfusion medium. Inside the left ventricle a balloon is closely fitted in the ventricular cavity and joined to an artificial systemic circulation. By the help of a cannula fluid present in the balloon is pumped into the closed extra corporal circulation being forcefully pumped into a single direction by 2 recoil valves. Silicone material, Teflon form is used to prepare the balloon. The fluid volume ejected from the balloon during each heartbeat, is equal to the stroke volume of the heart, and it can be recorded by help of an integrator and flow meter probe connected in series. Afterload and preload can be adjusted independently from each other. The perfusate flow (reversely moving into the aorta and through the coronary arteries is discretely recorded (Linz et al., 1986). In isolated rat hearts the following parameters were measured:

LVP (left ventricular pressure) is measured with Statham pressure transducer P 23 DB, which on differentiation yielded HR (heart rate) and LV $d p / d t$ max. Coronary flow (CF) and Cardiac output are measured by electromagnetic flow probes in the in the aortic cannula and outflow system, respectively. Coronary venous pO2 is determined by placing a catheter in the pulmonary artery by a type E 5046 electrode which is connected to a PMH $73 \mathrm{pH} /$ blood gas monitor (Radiometer). The recording of an epicardial electrocardiogram is obtained by the help of two silver electrodes attached to the heart. All parameters were recorded on a Brush 2600 recorder.

Myocardial oxygen consumption $\left(\mathrm{MWO}_{2}\right)$ $[\mathrm{mL} / \mathrm{min} / \mathrm{g}$ wet weight $]$ is calculated according to the equation:

$$
M V O_{2}=C F \times(P a-P v) \times(c / 760) \times 100
$$

where $C F$ is the coronary flow $[\mathrm{mL} / \mathrm{min} / \mathrm{g}], P$ a is the oxygen partial pressure of arterial perfusate $(650 \mathrm{~mm}$ $\mathrm{Hg}), P \mathrm{v}$ is the oxygen partial pressure of the venous effluent perfusate [mm Hg], and $c$ is the $0.0227 \mathrm{~mL} \mathrm{O}_{2} / \mathrm{mL}$ perfusate representing the Bunsen solubility coefficient of oxygen dissolved in perfusate at $37^{\circ} \mathrm{C}$ (Martorana et al., 1987).

\section{Coronary artery ligation followed by reperfusion}

In coronary artery blocking experiment, over a time span of 20 min (pre-ischemic period), modified KrebsHenseleit buffer are perfused in isolated working hearts at a constant pressure of $65 \mathrm{~mm} \mathrm{Hg}$. After that, left coronary artery is clamped near its origin for 15 min resulting in acute myocardial ischemia. Thereafter, clip is released, and various changes in myocardium are monitored for $30 \mathrm{~min}$ (reperfusion period). Ventricular fibrillation is developed in heart after coronary artery and reperfusion. Lactate, lactate dehydrogenase (LDH), and creatine kinase (CK) are determined from the coronary ejected sample.

Histopathological study can be done to estimate glycogen, ATP, creatine phosphate, lactate in the cardiac tissue. Before occlusion or $5 \mathrm{~min}$ before reperfusion the test drug are mixed into the perfusate. For ex vivo experiments, the rats are administered orally with the test drug just $1 \mathrm{hr}$ before the isolated working heart preparation and sacrifice (Scholz et al., 1992; Scholz et al., 1993). The efficacy and potency of cardioprotective drug is compared with control after treatment of ventricular fibrillation. Angiotensin II reduces the LV $d P / d t$ max, Left ventricular pressure, and coronary flow after coronary artery ligation and the myocardial content of glycogen, ATP and creatine phosphate are decreased due to increase in enzymatic metabolism in the effluent. Opposite effects are shown by the cardioprotective drugs. After completion the obtained data from each parameter is compared with control. Vleeming et al. (1989) performed thoracotomy in the presence of ether by tying the left coronary artery. After $48 \mathrm{hr}$ of surgery, by using Langendorff technique the heart was prepared for reversible constant pressure perfusion (Vleeming et al., 1989).

Igic introduced a new isolated working rats heart method in which a special designed double cannula is used, the outer cannula is inserted in the aorta and the inner cannula is inserted in the left ventricle. The perfusion fluid is allowed to reach left ventricle via inner cannula and is ejected out through aorta. When the outer cannula is closed the fluid passes through the coronary artery and oozes outside the heart. A small amount of perfusion fluid is perfused in the coronary artery and rest amount is expelled out, when a specific pressure resistance is applied and outer cannula is opened. Because the inner cannula can be easily removed from the outer cannula, which has been 
inserted in the aorta, this setup provides an opportunity to use the same heart as a "working" or "nonworking" model for identifying the working of the heart (Igić, 1996).

\section{Langendorff heart model}

German physiologist Skar Langendorff first proposed isolated heart model in 1895 for the physiological and pharmacological experiment on isolated heart. This method or apparatus is worldwide known as the The Langendorff heart apparatus or model. The basic agenda of Langendorff model was to provide oxygen and necessary metabolite through a single cannula inserted in the ascending aorta. By the help of an external pump the perfusate or the oxygenated blood is pumped into the heart by the help of a pump via aorta. This continuous cyclic supply shuts the aortic valve and during diastole allows the fluid to flow via coronary artery. Fluid moves through the coronary system and exit out in the right auricle via coronary sinus. $0.5-1.5 \mathrm{Liters} / \mathrm{min}$ is the rate of coronary flow required normally for an adult human heart.

According to the perfusion system Langendorff assembly is of two types:

Langendorff mode - The flow of bloods and metabolites into coronaries artery is determined by the external pump.

Working mode - The flow of bloods and metabolites into coronaries artery is determined by the contraction and performance of the heart. It can also be used for in vivo perfusion (Kumar et al., 2016). In a standard langendorff assembly, the heart is clamped via aorta against the cannula. The cannula size for rats and mice varies from 14 to 8 gauge (1.6 -3.2 $\mathrm{mm})$ to 22 and 16 gauge $(0.6-1.3 \mathrm{~mm})$ respectively. Before administering anesthesia and starting the mounting of the heart, heparin is injected in animal in order to prevent blood coagulation. Commonly used anesthetics are Injectable (pentobarbital, ketamine/ xylazine) and inhalable (isoflurane). The level of creatine phosphate and ATP decline rapidly in isolated heart that why cannulation process is done as soon as possible with the help of magnifying glass or section microscope in the perfusion system (de Leiris, Harding, Pestre, 1984). The degree of ischemia produced in the heart, directly depends and controlled by partial or complete blockage of blood supply to the heart. The molecular pathway in ischemia reperfusion injury can be understood by this method (Verdouw et al., 1998; Hernando et al., 2010).

Murry et al. (1986) explained the ischemic preconditioning phenomenon by using ex-vivo langendorff heart model, and stated that irreversible myocardial injury can be delayed, if the ligation was presage by the small duration of reversible myocardial ischemia (Murry, Jennings, Reimer, 1986). The entire procedure is summarised as, without flow of fluid (no flow) the ventricles contract and the left chambers of the heart is allowed to remain filled. According to Frank-Starling principle, the pressure inside the ventricles of heart is directly proportional to the force of contraction, In order to create a more physiological contraction of ventricles many scientist have tried to increase pressure inside the left ventricle. For example, the force of contraction and ventricular pressure has been increased by placing inflated balloon in the ventricles. Similarly, pressures have been increased by filling fluid in the ventricle while atrioventricular clamp has been used to prevent valvular regurgitation.

Following are the some advantages on in vivo MI models such as,

- $\quad$ Easy to understand the pathophysiological changes

- Well controlled environmental conditions

- Elimination of hemodynamic neurohumoral hindrances

Initially, the Visible Heart preparation depends upon constant pressure Langendorff perfusion inorder to supply the adequate oxygen and metabolites to cardiac muscles. However, without the presence of major arrhythmias, as the normal sinus rhythm has been achieved for long interval of time, the heart can be transferred into 4 chamber working model and Langendorff perfusion is stopped or re-established as required (Verdouw et al., 1998).

\section{In vitro models - isolated cardiac cells}

In in vitro models complete body or intrinsic impacts, for example, the extracellular condition, are removed. Less complicated frameworks offer several circumstances including giving the capacity to control and repeat disease pathology utilizing latest progressed natural procedures to additionally figure out disease pathology. Besides, in-vitro results give information which can be further approved by in-vivo work, this may refine the research procedure and as such favours the less use of experimental animals. With the progress in biotechnology the utilization of isolated heart myocytes in biochemical and electrophysiological study is rising (de Leiris, Harding, Pestre, 1984; Davie et al., 2004). Regularly cardiomyocytes are separated from cultured embryonic cells or grown-up cells by various 
techniques (Yu, Rodrigues, McNeill, 1997) for example, a langendroff perfusion strategy and enzymatic processing technique. Enzyme, for example, collagen type II, proteases and pancreatin are generally utilized compounds for digestion technique. Confined myocytes are put in a perspex chamber super joined with physiological salt solution (PSS), and blown with 95\% O2 and 5\% $\mathrm{CO} 2$. Field anodes are utilized for compression of cells monitoring by different detectors such as mechanical and photodiode cluster edge indicators (Roos, Brady, 1982). The Pharmacological intercessions are screened in an exact and controlled way. These models offers preferred advantages, for example, effortlessness, inexpensive miniaturisation, decreases animal use in experiments, utilize high-number of replica, quick/high throughput and generate reproducible data, enabling easy correlation with human diseases; cell models accessible for most tissue varieties, cell lines support reproducibility and encourage between lab examination (Kumar et al., 2016).

\section{In vivo}

Left anterior descending (LAD) coronary artery route ligation is most generally utilized surgical strategies for intense myocardial necrosis. Necrosis can be initiated by ligating distinctive area of the coronary supply route. This technique was first presented in 1954 by Johns and Olson et al and with couple of alterations, now broadly use in both small and large animals (Thomas, Johns, 1954). Mice and rats are usually utilized in laboratory for surgical ligation since they offer a various advantages over other rodents and animals (Srikanth et al., 2009). The surgical strategy involves a few stages; in short animals are anesthetized and lied down in the recumbent position. The left half of the sternum is cut horizontally alongside third and fourth inters costal muscle. Third and fourth ribs are isolated by retractor; heart is uncovered by pressing out and LAD coronary supply route is ligated by clean suture. Electrocardiography (ECG) is performed to approve the procedure; ST-segment height and whitish color of front left ventricle wall demonstrates induction of Myocardial Infarction. The fundamental confinements of this model are high death rate, post-surgical contamination and difference in infarct size from 4-59\%, necessity of master hands and artificial ventilator. Anyhow, this procedure has the mortality which was accounted to be over $50 \%$ because of malign ventricular tachycardia in the preliminary stage. Moreover, areas of necrosis are small much of the time (averaging $21 \%$ of the left ventricle), which is conceivably because of a high number of sub-pericardial collaterals in this species. Hence, just minor haemodynamic variations were observed (Hood, McCarthy, Lown, 1967). In addition, the model is tedious, costly and is criticised regarding animal protection efforts. Nonetheless, the use of this strategy in the pig caused a mortality of just $20 \%$, because mainly of intense ventricular tachycardias and ventricular fibrillation.

By altering the regular surgical technique, researcher overcome the previously mentioned impediments of LAD ligation and offer a few advantages, for example, survival rate of animals are increased, uniform necrosis size and prevent postsurgical disease (Iwanaga et al., 2004).

\section{Left ventricular MI}

The draft of left ventricular MI in rats has been introduced by Pfeffer et al. (1979). In short, after anesthesia, orotracheal intubation and thoracotomy, the heart is quickly exteriorised and the LCA is ligated in the proximal portion utilizing a thin thread. The blockage of the artery can be perceived by whitening of the tissue far from the ligation. Rats with areas of localized necrosis greater than $46 \%$ promotes congestive HF following 21 days with raised filling pressure, diminished cardiac output, and a negligible ability to react to pre-and afterload pressure. The level of weakness of LV work is specifically identified with the degree of myocardial loss (Pfeffer et al., 1979). The mortality is by all accounts strain reliant. In a comparative report the mortality of SpragueDawley rats was $36 \%$, while in Lewis innate rats it was fundamentally lower (16\%) (Liu et al., 1997). Now a day the mouse is the species progressively used to specify MI induced by coronary artery ligation. The surgical method to incite MI in the mouse is like the rodent model. Most instances of death happen inside $1 \mathrm{~h}$ after occlusion, presumably because of ventricular fibrillation and extreme intense HF (Klocke et al., 2007).

\section{Coronary artery ligation followed by reperfusion}

In 1995 Michael et al. initially depicted the open chest in vivo mouse model. Like the MI animal models, the coronary artery route is occluded with a piece of dampened umbilical tape (for large animals) or thread (for small rodents), yet a little plastic tube is set between the ligated vessel and a hub is used which account for easy and safe removal of ligation. Mice are anesthetized with phenobarbital (50 mg/kg, i.p.), placed in the recumbent position by taping the edges and the upper jaw. From the xiphoid process to the submentum a midline skin cut is made. After dissecting and isolating the salivary organs, the muscles overlying the trachea are withdrawn, and a 
tracheotomy is performed. A polyethylene tube (No. 90) is precisely embedded into the trachea (around $5 \mathrm{~mm}$ from the larynx), taped in place to prevent dislodgement and associated by means of a free intersection to a rat ventilator (display 687; Harvard Apparatus). After ventilation (tidal volume $1,2 \mathrm{~mL} / \mathrm{min}$., rate 110 strokes $/ \mathrm{min}$.) is started by supply of $100 \%$ oxygen the chest is opened by a sidelong cut along the left half of the sternum. A sufficient tidal volume brings about a satisfactory swelling of the lungs without overexpression. The entire procedure is performed under a magnifying lens (Olympus SZH 10). By the help of electrocoagulator, intercostal artery \& veins are coagulated. The chest wall is then open utilizing a 6-0 silk suture for better analysis of the heart. After removing the pericardial sac and then left auricle is slightly drawn back, leading to clearly visible of left descending artery (LAD). A $1 \mathrm{~mm}$ area of a PE-10 tubing is put over the LAD to secure its occlusion without harming the LAD. The LAD occlusion is finished with a 8-0 silk and ends up noticeably clear by staining of the left ventricle. The last end of the suture is expressed through each side of the chest wall, the chest is shut at last, the suture ends are tucked under the skin.

To prevent cooling of the animal, it is essential to utilize a warming cushion set under the mouse (Michael et al., 1995). At the time of ligation, the chest cut is secured with saturated dressing gauze to prevent drying and loss of heat (Vandervelde et al., 2006). After a specified time of LAD ligation, the occlusion can be evacuated by cutting the bunch over this PE-10 tube and reperfusion can be confirmed by visual evaluation. Ischemia can be identified by the sudden region based whiteness of the myocardium and ECG changes. Reperfusion is confirmed by the presence of hyperaemia in the previous white area. The total time period of coronary artery ligation is vital for the pathophysiological result: With increasing time of ligation the hazard for necrosis of the staggered myocardium increases.

\section{Minimal invasive ischaemia/reperfusion model}

The advantage of this in vivo model demonstrate with an implantable device for artery ligation is to beat the abnormal level of inflammation because of surgical injury related with the open chest model, allowing a more exact and interpretable reaction about the inclusion of various cytokines and other sources in the ischaemia/reperfusion damage of the myocardium (Lee et al., 1971).

After performing out a thoracotomy as portrayed in the open chest model, a 8-0 Surgipro monofilament polypropylene suture is passed under the LAD with the help of U-shaped tapered needle. The two edges of the suture are strung through a $0.5 \mathrm{~mm}$ bit of PE-10 tubing, shaping a free catch around the LAD, and are then strung through the end of a size 3 Kalt suture needle (Fine Science Tools) and extended through both side of the wall of chest. The chest is shut, and the blunt ends of the exteriorised 8-0 suture are then tucked under the skin. The rodent is expelled from the respirator and is permitted to inhale $100 \% \mathrm{O}_{2}$ through a nasal cone until complete state of consciousness.

\section{Ischaemia/reperfusion with ischaemic preconditioning}

Mill et al. have been among the principal researcher who exhibited the early period of ischaemic preconditioning in the myocardium in the in vivo mouse display. Likewise, it has been seen that scientist have utilized this concept and demonstrated its exceedingly viability in initiating a significant confinement of the myocardial injury. An 8-0 silk suture with a U-moulded needle is passed under the LAD after dissecting the pericardium. The LAD ligation ends up by apparently changing the colour to white of the left ventricle. For the preconditioning procedure over the $1 \mathrm{~mm}$ plastic tube the knot is fix carefully and loosen after the given time. During this process care should be taken that there must be no harm to LAD (Miller, Van Winkle, 1999).

For preconditioning, the mouse is allowed to pass through three cycles of $5 \mathrm{~min}$. Artery blockage followed by $5 \mathrm{~min}$. reperfusion, individually. After ten minutes, the animal is passed through $30 \mathrm{~min}$. of coronary ligation of the artery, followed by $2 \mathrm{hr}$ of reperfusion. By this method it is conceivable to exhibit a reduction of the infarct size around $50 \%$. The mechanism behind it is as yet not completely illustrated. Different pathways have just been depicted. Among the most vital reason behind it, is believed to be reactive oxygen species, isoforms of protein kinase $\mathrm{C}$ (PKC) and adenosine (Conci, Pachinger, Metzler, 2006).

\section{Electrical method}

The rats were anesthetized with the help of ether and placed on an analyzation board, and a $3-\mathrm{cm}$ longitudinal incision is made in the thorax, $2 \mathrm{~cm}$ to one side of the midline. The heart is uncovered by subperiosteal resection of the fourth and fifth ribs. On the surface of wall of left ventricle several burns are made by smoothly applying a 2-mm-tipped binding iron (Wahl Iso-Tip, Clipper Co., Sterling, Ill.) to the epicardium. The affected region is roughly $2-4 \mathrm{~mm}$ in measurement. The entry points are shut by stapling together the muscle and after that the skin. The whole task (opening, searing, and shutting) must 
be finished in less than $2 \mathrm{~mm}$. The rodent is then put in a cage where it can be seen easily while recovering. No debilitation or change in behaviour is seen in these rats, if any change is observed while recovering then it should be noted down (Adler, Camin, Shulkin, 1976).

\section{Coronary artery embolisations}

Another large animal model of ischemic cardiomyopathy is based on intracoronary embolisations with microspheres, agarose or polystyrene beads or the intracoronary injection of thrombin and autogenous blood with fibrinogen. In the approach developed by Sabbah et al. closed chest dogs undergo 3 to 9 cathetermediated intracoronary embolisations performed 1-3 weeks apart. Embolisations are discontinued when the left ventricular (LV) ejection fraction is less than $35 \%$. In this model the LV end-diastolic pressure (LVEDP) increases, accompanied by a significant raise of pulmonary artery wedge pressure and systemic vascular resistance. At 3 months after the last embolisation, the animals exhibit patchy myocardial fibrosis and LV hypertrophy, as well as increased plasma levels of atrial natriuretic peptide (ANP) and norepinephrine (Sabbah et al., 1991). The number of $\beta$-AR and L-type calcium channels decrease and the activity and protein levels of SR Ca2+-ATPase drops (Gengo et al., 1992). Coronary artery embolisations are induced percutaneously. Therefore, the risk of severe inflammatory complications following surgical interventions like thoracotomies is reduced. Moreover, this model resembles the clinical situation in patients with $\mathrm{HF}$ and acute coronary syndrome due to embolisation of atherosclerotic and thrombotic debris into the coronary microcirculation as well as the situation of patients with diffuse coronary artery disease such as in diabetes.

There is a limitation of the embolization technique stated that the exact location and length of coronary artery blockage is to be controlled.

Therefore, Reffelmann et al. (2004) designed a new method recently in which a negligible invasive way to induce chronic myocardial areas of localized necrosis in pigs: An adaptable body containing an open-cell froth sponge is percutaneously placed by means of a guide wire at a specific position in the coronary artery. Thus, the subsequent period in this investigation was just a single week and thus the safety and success of this strategy is to be proven by observing for a long interval of time (Reffelmann et al., 2004).

\section{Hydraulic occluder and ameroid constrictor}

These methods are especially used in larger animals (e.g. pig) allowing for the complete or partial occlusion of coronary artery branches. Accordingly, they are suitable to induce MI and HF (Harada et al., 1994; Roth et al., 1987), as well as coronary stenosis for the investigation of hibernating myocardium. For occluder implantation a left anterolateral thoracotomy is performed. After incision of the pericardium, a branch of the left coronary artery (LCA) is dissected and the hydraulic occluder is placed around the vessel. It is then inflated to induce partial stenosis or complete occlusion. To control the degree of occlusion and record the downstream flow through the LCA, an ultrasonic flow probe can be placed distally to the occluder during the same procedure (St Louis et al., 2000). An ameroid constrictor is implanted in a similar way but occlusion is achieved by a different mechanism. At body temperature, the ring around the vessel narrows gradually because of the hygroscopic property of the casein plastic material. As the hydraulic occluder the ameroid constrictor allows for the generation of big animal models for the investigation of MI-induced HF (Harada et al., 1994; Roth et al., 1987).

\section{Rat aortic banding}

Suprarenal aortic coarctation causes a short receptive hyperreninemia which last for less than 4 days. After that, the moving renin- angiotensin framework is not activated, yet the ventricular ACE movement starts to rise. As the time passes for several weeks, ventricular ACE movement may diminish again to ordinary esteems which might be identified with standardization of stress of coronary wall with expanding hypertrophy (Holtz et al., 1992). Various investigations have been performed utilizing aortic banding in rats to assess diverse parts of left ventricular hypertrophy. After several months, a failure is observed in a subset of animal. In a current report, interminable exploratory aortic tightening caused by banding of the ascending aorta in weanlings brought about repaid left ventricular hypertrophy of the grownup rats for half a month. Following 20 weeks of aortic banding two different groups could be distinguished: rats without change in development of LV systolic pressure and those with a high reduction in LV systolic pressure. The group with high reduction showed expanded left ventricular volumes, decreased ejection fraction and clinical indications of plain heart failure. Increase in size of left myocardium and failure was related with expanded $\beta$-myosin heavy chain mRNA and atrial natriuretic factor mRNA. Meanwhile, after 20 weeks of banding the level of SR-Ca ${ }^{2+}$-ATPase mRNA levels starts decreasing due to 
polymerase chain reaction which occurs in failing animals but not in nonfailing hypertrophied rat hearts.

From this information, it was proposed that the decline in SR-Ca ${ }^{2+}$-ATPase mRNA levels might be a indicator of the change from compensatory hypertrophy failure in animals (Feldman et al., 1993). During repaid hypertrophy, while catecholamine levels are in normal level, there is stimulation of the local myocardial reninangiotensin framework, which might be imperative for the advancement of myocardial failure. Plasma catecholamine levels can be increased with the development of heart failure (Hasenfuss, 1998).

\section{Cryogenic injury}

Cryogenic damage is another mouse model for contemplating heart recovery and cell re-modelling. Same as that of MI, the cryoinjury model show incites confluent injury however it does not leave extra cell in the centre of the inury. It can likewise have interdigitating suitable and injured tissue (Murry et al., 1996).

Research shows that cardiomyocytes have capability to multiply adequately to effectuate myocardial recovery after broad cryoinjury of the LV myocardium in grownup mice. Large amounts of macrophages moves and matches with the most high amounts of cardiomyocyte multiplication, recommending a beneficial role of these cells in myocardial recovery (van Amerongen et al., 2008). Cryogenic damage can be incited at various places all through the heart, depending upon researcher's area of interest. An open thoracotomy approach is utilized to prompt cryoinjury on the LV, because the freezing procedure can be directly visualized and quick validation of the subsequent frosting damage. A liquid nitrogencooled aluminium probe is connected specifically onto the front LV for $\sim 10$ seconds. The solidified myocardium defrosts totally 10-15 seconds following probe evacuation, and the damaged zone displays a dark red colour (Robey, Murry, 2008).

Another approach is through a stomach incision to prompt cryoinjury on the right ventricle (RV). Mice are anesthetized and the midriff is opened through a transverse laparotomy. The translucent stomach is uncovered by lifting the chest with a divaricator. The surface of the heart is presently noticeable through the stomach and the region in which damage is to be done is selected. A blunted tip stainless steel Von Graefe snare is specifically set on the stomach subsequent to cooling for $\sim 2$ min in fluid nitrogen to make an apical or midventricular RV damage. Two successive 10-s exposures (with an irregular 30-s inteval) cause a broad, transmural sore on the lateroapical part of the RV wall with an ex-pressure to the apical LV wall. A single 30-s exposure causes a broad, transmural lesion on the midventricular RV wall with no ex-strain to the septum (Grisel et al., 2008).

Genetically Modified Mice: With the improvement of hereditarily changed mice, the scientific comprehension of disease components and procedures has extraordinarily advancement in the field. These advantages would have been extensively delayed utilizing entirely in vitro research assay. Atherosclerosis is the key factor in charge of progression and precipitation of ischemic heart disease. In wild mouse acceptance and improvement of atherosclerotic model is common. This confinement can be reduced by accessibility of knockout and transgenic mouse models.

These animal models add to a more deep comprehension of the science of atherosclerosis and empower new instruments and pharmacological examinations to enhance current treatment of myocardial necrotic tissue (Hasty et al., 2001).

a) Knockout Mouse Model: This is a genetically modified model of mouse in which a specific gene is targeted and is "knocked out". Thus the gene which has been knocked out loses its activity and this leads to change in the phenotypes of mouse. When the genes of low-density lipoprotein receptor (LDLR gene) is removed it results in LDLR-deficient mice (LDLR-/- mice) while the removal of APO lipoprotein $\mathrm{E}$ (ApoE gene) leads to ApoE-deficient mice (ApoE-/- mice). Removal of COX-1 and 2 genes, leads to development of COX-1 and 2 deficient mice and these mice plays a major role in screening of antiplatelet drugs.

(i) LDLR-/- Mice: The LDLR-/- mouse resemble a animal model of common hypercholesterolemia because of mutation which affect the LDLR, while the lipoprotein found in plasma resembles that of human. ApoB and ApoE contain lipoproteins and a major role is played by LDL receptor in the clearance of the same containing lipoproteins. These mice are hereditary deficient in low density lipoprotein receptor (LDLR). This deficiency leads to various phenotypic changes such as change in lipoprotein metabolism, rise in high cholesterol level which is same as that of hypercholesterolemia of humans. Symptoms like rise in plasma cholesterol level, slow clearance in VLDL and HDL from atherosclerotic wound and plasma on coronary arteries are seen in mice after feeding a normal chow diet. Earlier research report suggest that LDLR-/- mice when feeded on regular chow diet 
show medium lipid levels and develops very less amount of atherosclerosis, but when the same diet is feeded for around 8 month, then drastic rise in cholesterol level with some marked wound near aorta. Thus we can conclude it as the grade of hypercholesterolemia and atherosclerotic sore in LDLR - / - mice can be increased by administering a high fat diet, a high cholesterol diet (Bentzon, Falk, 2010), by using mutagens for apoB genes for permanent removal (Véniant et al., 1998) and by crossing with leptin-deficient mice (Hasty et al., 2001) or with apoB100 transgenic mice (Sanan et al., 1998). But the response shown after treatment with hypolipidemic drugs differs in both LDLR $-/-$ and LDLR $-/-$ apoE $-/-$ mice and varies from reduction of plasma cholesterol or without reducing plasma cholesterol without decrease in atherosclerosis (Zadelaar et al., 2007). Some scientist found that when LDLR - - - mouse are treated with agonists of peroxisome proliferator-activated receptor (PPAR) or liver X receptor (Li et al., 2000) shows a huge fluctuation in response, and stated that this model can't be a standard for screening of anti hyperlipidaemic drugs (Plump et al., 1992).

(ii) ApoE-/- Mice: Apo E gene plays an important role in the management of lipid metabolism and development of atherosclerosis. ApoE-/-mice were first generated in 1992 by knocking out ApoE gene resulting in a huge rise in the plasma level of LDL and VLDL because of the clearance through the LDLR and LDLR-related proteins stating the same pathophysiological growth of atherosclerotic sore as humans (Hu et al., 2005). The VLDL particles are the main lipoprotein in ApoE-/- mice which plays a crucial role in stimulating atherogenesis in this animal model. Female mice are more susceptible to atherosclerotic injury and the most common site for injury are aortic root, aortic band followed by left coronary arteries. The ApoE-/- mice are usually cross breeded with other transgenic mice in order to understand the response of other genes on development of atherosclerotic plaque. The anti-atherosclerotic activity of Statins, a prominent antilipidemic drugs have been successfully done by using ApoE-/- mice.

Furthermore, the apoE $-/-$ mouse serves as an important tool to:

(i) Identify and specify atherosclerosis sensitive-causing genes, by the candidate-gene and gene-mapping methods,

(ii) Analysing various molecular mechanism and types of cell involved in atherogenesis,

(iii) Find out effect of drugs on atherosclerosis, and

(iv) Identify and discover novel therapies that prevent injury progression.

The apoE $-/-$ mice are now a days the most commonly utilized animal model for the screening of atherosclerosis. In fact, the response of large number of genes on the progress of atherosclerosis has been identified by cross over the apoE-/- mice with other genetically altered rodents (Zaragoza et al., 2011).

b) Transgenic Mice: Transgenic methodologies have provided a large series of very fruitful model of mouse for the study of atherosclerosis and hyperlipidemia. Among all these, ApoE mice resulted after mutation such as apoE3Leiden (E3L) and $\operatorname{apoE}($ Arg 112 $\rightarrow$ Cys $\rightarrow 142)$ crossed mice, are more commonly used for the study. These mice shows a lipoprotein profile which can be compared to that of patient with dysbetalipoproteinemia, in which total plasma and cholesterol level are restricted to VLDL (Hofker, van Vlijmen, Havekes, 1998). The E3L genetically altered mice develops atherosclerosis injury with the same symptom of human vasculopathy, thus varying from thick to mild and to narrow plaque formation (Leppänen et al., 1998). Furthermore, E3L genetically altered mice and recently the most crossed E3L/Cholesteryl ester transfer protein (CETP) transgenic mice have been showing more sensitivity to a large number of antihyperlipidemic drugs and PPAR agonists than apoE-/- and LDLR - - - mice (Van Der Hoorn et al., 2009). Advantages and disadvantages of various myocardial infarction models has been outlined. (Table I).

\section{Chemical methods}

Chemotherapy with certain cytotoxic medications is related with serious symptoms, for example, cardiotoxicity. As these symptoms can be dose dependent and cause extreme morbidity and even mortality. Getting knowledge about their chance and mechanism of occurrence of side effect is imperative. Cardiotoxicity can happen as intense or as long term adverse effect. With expanding survival rates, now a day's scientists are focussing to avoid the late onset of diseases and its severe effect.

Anthracyclines, for example, doxorubicin and epirubicin are known for their cardiotoxic adverse effect and extensive research is done to investigate the component of anthracycline mediated cardiotoxicity. Other cytotoxic medications that have shown cardiotoxicity are 5-fluorouracil, cisplatin, paclitaxel and docetaxel and some latest drug such as, monoclonal antibody trastuzumab. Till date the most common speculation for this type of side effect or toxicity is alleged as 'free radical' 
TABLE I - Advantages and disadvantages of various myocardial infarction models

\begin{tabular}{|c|c|c|c|}
\hline Methods & Models & Clinical Advantage & Clinical Limitation \\
\hline & $\begin{array}{l}\text { Coronary artery ligation in } \\
\text { isolated working rat heart }\end{array}$ & $\begin{array}{l}\text { - It allows the consctruction of cardiac function curve } \\
\text { under various conditions. } \\
\text { - Irriversible damage occurs after shorter period of } \\
\text { ischemia; all neurogenic and hormonal influences } \\
\text { are removed. }\end{array}$ & $\begin{array}{l}\text { - Complicated process. } \\
\text { - Chance of tissue death is maximum. } \\
\text { - Exact position of coronary artery ligation } \\
\text { has been not mentioned in literature. }\end{array}$ \\
\hline & $\begin{array}{l}\text { Coronary artery ligation } \\
\text { followed by reperfusion }\end{array}$ & $\begin{array}{l}\text { - Perfusion fluid volume and content are easily } \\
\text { controlled } \\
\text { - Metabolic substrates are conserved because only a } \\
\text { small amount of tissue is being perfused. } \\
\text { - Decreases the variation in infarct size following } \\
\text { surgery } \\
\text { - Decrease the incidence of excessive bleeding during } \\
\text { the operation. }\end{array}$ & $\begin{array}{l}\text { - Invasive and } \\
\text { - Time consuming approach } \\
\text { - Results in extensive tissue damage and } \\
\text { high mortality }\end{array}$ \\
\hline & $\begin{array}{l}\text { In vitro models -Isolated } \\
\text { Cardiac Cells }\end{array}$ & $\begin{array}{l}\text { - It permits works with homogeneous cell population. } \\
\text { - effortlessness } \\
\text { - Inexpensive miniaturisation } \\
\text { - Decreases animal use in experiments } \\
\text { - Utilize high-number of replica } \\
\text { - Quick/high throughput and generate reproducible } \\
\text { data. } \\
\text { - Enabling easy correlation with human diseases. }\end{array}$ & $\begin{array}{l}\text { - It usually cut off from the other types of } \\
\text { cell. } \\
\text { - Resemblance to human varies to greater } \\
\text { extent. }\end{array}$ \\
\hline \multirow{5}{*}{ In vivo } & Left ventricular MI & $\begin{array}{l}\text { - Mimics same physiological changes as compared to } \\
\text { human. }\end{array}$ & $\begin{array}{l}\text { - Tedious process. } \\
\text { - Skill hand required. }\end{array}$ \\
\hline & $\begin{array}{l}\text { Minimal Invasive } \\
\text { Ischaemia/Reperfusion } \\
\text { Model }\end{array}$ & $\begin{array}{l}\text { - Reduction of the abnormal level of inflammation } \\
\text { which occurs in previous model. } \\
\text { - Blood loss is reduced. } \\
\text { - High survival rate. }\end{array}$ & $\begin{array}{l}\text { - Low reproducibility of infarct } \\
\text { - High variability of infarct size }\end{array}$ \\
\hline & $\begin{array}{l}\text { Ischaemia/Reperfusion } \\
\text { with Ischaemic } \\
\text { Preconditioning }\end{array}$ & $\begin{array}{l}\text { - Early phase protection. } \\
\text { - Performed before the onset of prolonged myocardial } \\
\text { ischaemia. } \\
\text { - Highly effective tool to reduce lethal myocardial I/R } \\
\text { injury. }\end{array}$ & $\begin{array}{l}\text { - No significant effect on limiting the } \\
\text { degree of contractile dysfunction. } \\
\text { - Restricted to various cardiovascular } \\
\text { surgical procedures }\end{array}$ \\
\hline & Electrical method & $\begin{array}{l}\text { - Size of infarction can be controlled. } \\
\text { - Infarction can be done at a targeted place. }\end{array}$ & $\begin{array}{l}\text { - Special device required. } \\
\text { - Requires skilled person. }\end{array}$ \\
\hline & $\begin{array}{l}\text { Coronary artery } \\
\text { embolisations }\end{array}$ & $\begin{array}{l}\text { Resembles the clinical situation in patients with HF } \\
\text { and acute coronary syndrome due to embolisation } \\
\text { of atherosclerotic and thrombotic debris into the } \\
\text { coronary microcirculation as well as the situation of } \\
\text { patients with diffuse coronary artery disease such as } \\
\text { in diabetes. } \\
\text { - Control of the exact location and length of coronary } \\
\text { artery occlusion }\end{array}$ & $\begin{array}{l}\text { - Exact Location of infarction is } \\
\text { unpredictable. } \\
\text { - Reproducibility of infarction varies very } \\
\text { much }\end{array}$ \\
\hline
\end{tabular}


TABLE I - Advantages and disadvantages of various myocardial infarction models (cont,)

\begin{tabular}{|c|c|c|c|}
\hline Methods & Models & Clinical Advantage & Clinical Limitation \\
\hline & $\begin{array}{l}\text { Hydraulic occluder and } \\
\text { ameroid constrictor }\end{array}$ & $\begin{array}{l}\text { - More controlled shunt closure } \\
\text { - Its availability in various sizes to accommodate the } \\
\text { anatomy and size of the vessel to be constricted } \\
\text { - The surgery is a relatively simple procedure } \\
\text { - The post-operative monitoring is minimal, since } \\
\text { there are no external devices to maintain. }\end{array}$ & $\begin{array}{l}\text { - Variability in the rate of occlusion } \\
\text { - Ameroid placement causes mechanical } \\
\text { trauma, inflammation, fibrosis, and } \\
\text { thrombus formation. }\end{array}$ \\
\hline & Cryogenic injury & $\begin{array}{l}\text { - The lesion is highly reproducible in size, location } \\
\text { and pathophysiological processes }\end{array}$ & - Very sophisticated process \\
\hline \multirow[t]{2}{*}{ In vivo } & ApoE-/- Mice & $\begin{array}{l}\text { - Complex vascular lesions readily develop in animals } \\
\text { fed the normal low fat rodent chow, even when } \\
\text { plasma cholesterol levels are between } 300-500 \mathrm{mg} / \\
\text { dl. } \\
\text { - These lesions are comparable to human lesions. }\end{array}$ & $\begin{array}{l}\text { - Plasma cholesterol is mostly carried on } \\
\text { lipoprotein remnants rather than the LDL, } \\
\text { affecting macrophage biology, immune } \\
\text { function and adipose tissue biology. }\end{array}$ \\
\hline & Transgenic Mice & $\begin{array}{l}\text { - Contain extra genetic material integrated into the } \\
\text { genome in every cell. } \\
\text { - Generated to carry cloned oncogenes provide good } \\
\text { model for human cancer } \\
\text { - Good models for muscle growth study by } \\
\text { overexpressing the transgene insulin-like Growth } \\
\text { factor in differentiated muscle fibers. }\end{array}$ & $\begin{array}{l}\text { - Transgene integration is apparently } \\
\text { random } \\
\text { - Many experiments reveal that the genetic } \\
\text { surrounding of the inserted transgenic } \\
\text { construct is modulating the expression } \\
\text { pattern of the transgene itself both } \\
\text { qualitatively and quantitatively. } \\
\text { - Transgenic rescue of knockout mice is } \\
\text { time- consuming, expensive and labour } \\
\text { intensive. }\end{array}$ \\
\hline
\end{tabular}

hypothesis. However, defensive measures following this hypothesis, for example, such as administration of free radical scavengers have not gave off an impression of being clinically effective. The cancer prevention agent and iron chelator dexrazoxane has been effectively connected to shield the myocardium from cardiotoxicity with high dosage anthracycline treatment, but one has to be known that complete abolishment of cardiotoxicity can't not be accomplished (Schimmel et al., 2004).

Catecholamines are the key mediator of myocardial contraction and metabolism. The pathogenesis of the catecholamine-induced myocardial injury depends upon large number of factors; catecholamines play an important part in cardiac physiology. While catecholamines have been utilized successfully in clinical pharmacology for the treatment of pump disorder, over discharge or administration of catecholamines more than normal physiological dosages may drain or break the stored energy of heart muscle cells that prompts complex biochemical and resulting various structural changes that proceed from reversibility, called likewise degeneration irreversibly onto necrosis.

Cardiotoxicity incorporates an extensive range of heart impacts starting from little changes in blood pressure followed by arrhythmias to cardiomyopathy. Literature supports various different mechanism of chemotherapy causing cardiotoxicity are hypothesized including cardiac cell damage due to generation of free oxygen radicals and 
the initiation of immunogenic responses due presence of antigen carrying cells in the heart (Lipp, 1991).

\section{Isoprenaline}

Isoprenaline was first used by George Rona to produce a infarct in rats (Rona, Kahn, 1969). It is a synthetic catecholamine and a potential $\beta$-adrenergic agonist, caused severe stress on the myocardium resulting in infarction like injury of the cardiac muscles and finally precipitating MI when administered in large dose. Various mechanism of ISO are postulated in causing myocardial infarction that includes hypoxia due to hyperactivity of myocardium and fall of pressure in coronary arteries, overload of calcium, and removal of high energy phosphate as well as production of free radicle because of auto oxidation of catecholamine leading to membrane peroxidation. The pathophysiological and morphological changes in occurring in myocardium after isoprenaline administration in rats is same with those changes which takes place in humans (Amran et al., 2015).

\section{Aluminium chloride}

Aluminium (Al) is comprehensively scattered all throughout the environment. It is commonly utilized in daily life making its easy exposure to animals and human beings. Al sources are obtained from corn, yellow cheddar, salt, herbs, spices, tea, beauty care products, and containers. It has been accounted for that $\mathrm{Al}$ could be collect in all tissues of living being, specially in liver, heart, bones and cerebrum. This metal disturbs the prooxidant/cell reinforcement balance in tissues prompting biochemical and physiological dysfunction because generation of excessive reactive oxygen species (ROS). When the body is exposed to high dose of aluminium it reduces the activity of I, II and IV of electron transport chain prompting the debilitation of mitochondrial energy production and oxidative damage. Oxidative stress may play a critical part in heart and vascular abnormalities in various types of cardiovascular diseases. The mechanism through which Al produces cardiotoxicity impacts might be ascribed to oxidative stress and causing disturbance in the intracellular redox framework. The exact mechanism of Al mediated toxicity is not yet been clear, but some correlates it with prooxidant properties of aluminium. With an end goal to enhance our comprehension on aluminium toxicity on heart mechanism, scientist have assessed the cardioprotective impact of selenium by overseeing aluminum chloride ( $50 \mathrm{mg} / \mathrm{kg} \mathrm{bw})$ for 21 days to deliver cardiotoxicity (Ghorbel et al., 2017).

\section{Azithromycin}

The macrolide antibiotics, when administered both in combination and alone with different medicine, may once in a while cause cardiotoxicity, for example, delayed QT interval and polymorphic ventricular tachycardia. Azithromycin, which is a broad range second generation macrolide group of antibiotics with negligible side effect and a pharmaco-dynamic/pharmacokinetic profile that permits simple dose regimens, is now used as a treatment of bacterial infection, despite the fact that uncommon types of cardiotoxicity has been proposed with the azithromycin treatment when compared with other macrolide subsidiaries, the instances of cardiovascular side effect related with azithromycin have drawn attention in recent time. Azithromycin promotes oxidative stress \& this occurs due to a disruption in the antioxidant defence system and an increase in the generation/production of reactive oxygen species in the cases of infarction. This further leads to the changes in the cardiac functions and the functions of ion channels, ionic pumps, ion exchangers, and inflammatory processes have been suggested to be associated with the oxidative stress.

As indicated by the information from the adverse impact notice system of FDA (Food and Drug Administration), azithromycin related with 20 cases of Torsades de pointes have been accounted. Moreover, as indicated by the reports of the cohort investigations led on the patients who got azithromycin treatment, it was accounted for that there had been sudden deaths because of ventricular arrhythmia due to irrational azithromycin use. In spite of the fact that there are case reports attracting attention to the cardiovascular adverse effect related with the treatment of azithromycin, there was no exploratory investigation assessing cardiotoxicity in simultaneous pharmacological dose of azithromycin until Atli et al. assessed azithromycin $(15 \mathrm{mg} / \mathrm{kg}$ and $30 \mathrm{mg} / \mathrm{kg}$, for 14 days) incited cardiotoxicity and they expressed that azithromycin in simultaneous pharmacological dose was determined to cause adverse effect in relation to plasma cardiovascular biomarkers and ECG parameters and histopathological examination (Atli et al., 2015).

\section{Bupivacaine}

Bupivacaine is a local anesthetic drug which is widely used now a day because of long duration of action and potency. Unfortunately, bupivacaine causes severe cardiotoxicity when accidentally administered intravenously. Several serious cases of cardiac arrest have been reported with the use of bupivacaine repeatedly. 
Bupivacaine has prolonged myocardial sodium channel blocking properties because it metabolises from channels slowly during diastole when compared to lidocaine which binds and degrades fast. Previous research shows that lidocaine could replace bupivacaine from its receptor and some scientist states this property of lidocaine to be used during bupivacaine cardiotoxicity. It reduces the availability of fatty acids for $\beta$-oxidation in myocardial mitochondria by specific inhibition of the enzyme systems involved in the carnitine shuttle. The resulting loss of energy substrate potentially could contribute to the cardiotoxicity observed clinically. Research also states that conduction blockade by inhibiting $\mathrm{Na}^{2+}$ channel and negative inotropy is also promoted by bupivacaine.

Basically animal study support this theory of replacement. Bupivacaine were investigated on a spontaneously beating isolated rat heart model for its Cardio toxic effects. The report shows that the mixture of both bupivacaine and lidocaine (bupivacaine $6 \mu \mathrm{g} /$ $\mathrm{mL}, 21 \mu \mathrm{M}$ and lidocaine $12 \mu \mathrm{g} / \mathrm{mL}, 51 \mu \mathrm{M}$ ) disturbs the Intraventricular conduction parameters (prolonging QRS interval) to a small amount than bupivacaine (6 $\mu \mathrm{g} / \mathrm{mL}, 21 \mu \mathrm{M})$ ) itself, and this effect has been noted in the beginning of perfusion (Krrikava et al., 2010). The role of mitochondrial KATP channels in lipid rescue of bupivacaine-induced cardiotoxicity has been studied (Partownavid et al., 2013).

\section{Carbon tetrachloride}

Carbon tetrachloride (CC14), is a clear, colourless, volatile, heavy and non-flammable liquid, is a well-known ideal compound for causing chemical induced cellular toxicity by production of free radicals in various tissue tissues (Adaramoye, 2009). The most accepted mechanism of $\mathrm{CCl} 4$ induced cardiotoxicity is the production of free radicals which is a rate limiting process in cellular peroxidative damage. This free radical and other related oxidative species may cause oxidative stress, which produces the major interrelated changes in cellular metabolism, thus increasing the level of calcium inside the cell. Causes damage to the permeability and transport of ions through membrane and also destroy the cell by lipid peroxidation. A report suggest that injecting CCl4 $(1 \mathrm{~mL} /$ $\mathrm{kg}$ i.p. for 16 days) to rats may cause damage to heart and causes the increase in level of the lactate dehydrogenase (LDH) and creatine kinase $\mathrm{CK}$ and malondialdehyde (MDA) level and reduces the level of antioxidant enzyme basically SOD, CAT and GPx level in heart indicating that heart can be targeted by CC14.(Eshaghi et al., 2012) Other experiment suggest that $\mathrm{CCl} 4$ was when induced into the rats $(1 \mathrm{~mL} / \mathrm{kg}, 5$ th -8 th weeks (twice a week), i.p route.) resulted into marked uptake and accumulation of $\mathrm{CCl} 4$ in the cell, the mechanism behind it was postulated as generation of free radical \& development of oxidative stress in the myocardium (Uttam Paul, 2016).

\section{Chlorpyrifos}

Organophosphorus pesticides constitute a vast group of pesticides and they are utilized generally to control pest in the house, crops and urban condition. Chlorpyrifos is a wide range organophosphate pesticides used broadly in agribusiness and for controlling pest in house throughout the world under various enlisted trademarks. Chlorpyrifos, as other organophosphates, shows its toxic impacts basically by hindering the activity of enzyme acetylcholinesterase. Xenobiotics, including insecticides, are known to stimulate the production of receptive oxygen species (ROS), which causes oxidative stress in various tissues. Chlorpyrifos have different effect on the cell including release of reactive oxygen species and enlistment of intracellular oxidative pressure in such manner that it disturbs the normal cellular structure and multiplication of cardiomyocytes. Chlorpyrifos is additionally known to create oxidative stress thus causing accumulation of lipid peroxidation residue in various organs of rats and initiate histopathologic changes in various tissues. Study demonstrated that low dosage of chlorpyrifos $(5.4 \mathrm{mg} / \mathrm{kg}$ bw, 4 week) causes cardiac toxicity, chlorpyrifos causes major changes in the properties of antioxidant enzymes in rats (Baş, Kalender, 2011).

\section{Cisplatin}

Cisplatin (Cis-diamminedichloroplatinum) is a platinum-conjugated anti-carcinogenic drug that is regularly utilized as a part of the treatment of solid tumors. The therapeutic impact of $\mathrm{CP}$ rises noticeably with increasing the dose. Then again, the clinical utilization of CP has been constrained because of expanded oxidative stress, and symptoms (nephrotoxicity, cardiotoxicity) because of apoptosis. $\mathrm{CP}$ react with DNA, and causes intra- and inter-cross linkage. The subsequent DNA produced starts apoptosis. Study demonstrated the cardiotoxic response of cisplatin may cause electrocardiographic changes, toxic effect of free radicals, mitigate the lipid peroxidation which was diminished by concentrate of grape seed proanthocyanidins (Lian et al., 2016). Expanded oxidative stress and histopathological injury have been involved in the cardiotoxicity that constrains the clinical 
use of cisplatin $(\mathrm{CP})$ as an anti-cancer drug which was then analysed by managing cisplatin administration after treatment by hesperidin (Oguzturk et al., 2016).

\section{Clozapine}

Clozapine, a tricyclic dibenzodiazepine, is an atypical antipsychotic medication that is exceptionally viable in treating psychosis, especially in those patients in which other drugs are inefficient. It has potent antagonistic properties on D4-dopaminergic receptor, serotonergic, noradrenergic, histamine and cholinergic M2 receptors. But sometimes, some antagonistic impacts of clozapine have constrained its clinical importance. A typical and common antagonistic impact requires severe monitoring of its cardiotoxicity. The mechanism behind clozapinemediated cardiotoxicity isn't yet fully comprehended but demonstrate a possible IgE-mediated hypersensitivity response demonstrated an increase in the level of receptive oxygen species (ROS), Certain cytokines, for example, tumor necrosis factor- $\alpha$ (TNF- $\alpha)$ in the myocardium, clozapine-mediated cardiotoxicity was presented in rats by regulating a measurements of 10,15 and $25 \mathrm{mg} / \mathrm{kg} /$ day, i.p. for 21 days. It causes genuine and deadly problems during the entire clozapine treatment in rats. Increased myocardial oxidative stress, cytokines causing inflammation, cell and DNA injury and apoptosis with weakening in antioxidant defence are largely contributing components. This requires a high level of clinical care through the course of clozapine treatment. The utilization of echocardiographic (ECG) observing as a standard periodical check over the span of clozapine treatment, and biohumoral examination if any indications of cardiotoxicity begins to appear is suggested (Abdel-Wahab, Metwally, 2014).

\section{Cyclophosphamide (CP)}

It is broadly utilized as an antineoplastic and immunosuppressant medication. It is utilized for the treatment of constant and intense leukaemia's, different myeloma, lymphomas, and rheumatic joint inflammation and in preparation for bone marrow transplantation. In spite of the fact that it has tumor selectivity and wide range of clinical uses, $\mathrm{CP}$ is known to cause lethality in multiple organs. High dosage of $\mathrm{CP}$ when administered can cause a severe type of cardiotoxicity within 10 days which shows as a blend of manifestations and indications of myopericarditis prompting lethal complications, for example, congestive heart failure, arrhythmias, cardiovascular tamponade and myocardial depression.

Cyclophosphamide quickly disturbs the cellular respiration and furthermore harms the internal mitochondrial layer of heart prompting the penetrability of calcium ion is mediated by oxidative stress. Cyclophosphamide initiated cardiotoxicity has been involved in increasing the production of superoxide radicals and hydrogen peroxide. These receptive oxygen species (ROS) injure the heart by surpassing the oxygen radical detoxifying limit of cardiovascular mitochondria. In this manner, the antioxidant treatment might be helpful in the administration of CP incited cardiotoxicity. Latest research demonstrates that the $\mathrm{CP}(200 \mathrm{mg} / \mathrm{kg}$, i.p. single measurements) treatment promotes heart weight and diminished body weight in rats (Viswanatha et al., 2013). Research demonstrates that Cardiotoxicity was showed after the rats were administered cyclophosphamide $(150 \mathrm{mg} / \mathrm{kg}$, i.p.) causing severe blockage, oedema and extravasation in the cardiovascular tissues, and in addition a specific leucocytic penetration is obtained by visible and histopathological examination (Gado et al., 2013).

\section{Doxorubicin (DXR)}

It has been demonstrated that doxorubicin (DXR), an anthracycline antibiotic having broad spectrum against numerous malignancies, has restricted clinical use due to its cardiotoxicity. Utilization of DXR brings about changes in blood pressure and heart rate and additionally loss of contractility. It was exhibited that DXR cardiotoxicity brings about interruption of myocyte structure, including injury to the microtubules, vacuolization, sarcomere disturbance, dilatation of the sarcoplasmic reticulum, mitochondrial damage and loss of myofibrils. Oxidative injury to membrane lipids and other cellular component is sought to be a main consideration in DXR toxicity. Doxorubicin causes myocardial injury by means of the development of free oxygen radicals. In normal healthy conditions free oxygen radicals are effectively detoxified by antioxidants enzyme, for example, superoxide dismutase (SOD), catalase (CAT) and glutathione peroxidase (GSH-Px). In any case, when there is an imbalance between the production of oxidants and the particular defence frameworks of the organism, the enlistment of lipid peroxidation and modification in intracellular homeostasis takes place, as observed in DXR-mediated cardiotoxicity. Research shows that in rats ultrastructural adjustments was actuated by Doxorubicin $(10 \mu \mathrm{mol} \mathrm{kg} /$ day/i.p.) in numerous organelles, including disturbance of mitochondrial fine structure (Fadillioglu et al., 2004). Other research recommends about doxo mediated dose dependent toxicity in which doxo was given alone (6 and $15 \mathrm{mg} / \mathrm{kg}$ ) and in combination (Shahzadi et al., 2014). 


\section{Gamma radiation}

When a body is exposed to radiotherapy, ionizing radiation communicates with biological frameworks of the body to deliver free radicals or reactive oxygen species (ROS), which causes injury to different cellular segment including DNA, proteins and membrane lipids, prompting chronic cellular injury. ROS likewise negatively affect the cell antioxidant protection systems, diminish the intracellular accumulation of glutathione (GSH) and reduction the efficacy of superoxide dismutase (SOD), catalase (CAT) and glutathione peroxidase (GSHPx) (Azab et al., 2011) found that radiation may cause the production of ROS that associates with biological molecules and producing less toxic free radicals. The final yield of peroxidation is malondialdehyde (MDA), significant aldehyde compound that is mutagenic in cells and could be identified to assess tissue damage.

Plasma lipids level is increased by day 6 post radiation; plasma cholesterol, triglycerides (TG) level were increased. Additionally low density lipoprotein (LDL) was increased and accumulated in plasma while high-density lipoprotein (HDL) level was diminished. The introduction of the human body to ionizing radiation causes breakdown of endogenous antioxidant and dependable antioxidant that can secure tissues against radiation-mediated injury. Reports showed symptoms of cardiotoxicity when rats were exposed with a solitary measurement level of (10 Gy) radiation transferred at a dosage rate of $0.46 \mathrm{~Gy} / \mathrm{min}$. at the time of experiment (Elkady, Mohamed, 2016).

\section{Imatinib}

Imatinib, is a best example of small molecule therapy drug, and has set a benchmark in the treatment of endless myeloid leukaemia (CML), and is currently prescribed as standard treatment for the fast growing and chronic stage infection, and additionally for the treatment of cutting edge gastrointestinal stromal tumors (GIST). Research data demonstrates that serious cardiotoxicity of imatinib in both a clinical setting and under exploratory conditions has been completely documented. It is a tyrosine kinase inhibitor (TKI), current TKI drugs distort fundamental pathways regulating the mitotic development of tumor cells. These same pathways have been distinguished as additionally being essential for keeping up the cells alive in typical tissues, for example, the heart. Studies stating Imb-mediated cardiovascular injuries depict different types of morphological changes in myocyte. Imb-mediated heart alteration was studied, in which male spontaneously hypertensive rats (SHRs) were administered with oral dose of 10,30 , or $50 \mathrm{mg} / \mathrm{kg} \mathrm{Imb}$ or water day by day for $10 \mathrm{~d}$. Cardiac sores, identified at all doses, were stated by cytoplasmic vacuolization and myofibrillar loss. Other experiment suggest that, Cardiac injury were identified in Sprague Dawley (SD) and SHR rats when administered 50 or $100 \mathrm{mg} / \mathrm{kg}$ Imb for $14 \mathrm{~d}$ (Herman et al., 2011).

\section{Lead and Mercury}

Heavy metals are a group of natural chemicals which possess several toxic effects on living beings. In spite of the fact that metals have adverse effect when exposed to living organism, their use and importance is continuously expanding. Expose to heavy metals has been connected to increase the risk of cardiovascular problem. Mercury, an outstanding toxic substance, causes toxicity through interaction with cell thiols and the generation of responsive oxygen species (ROS). These ROS incorporate superoxide, hydrogen peroxide and also hydroxyl radicals.

ROS instigate cell dysfunction through oxidative injury in membrane lipids and proteins. Lead is an essential natural poison that actuates a wide scope of physiological, biochemical, and behavioural dysfunctions. It can prevent biological functions by altering the molecular communications, cell function and cell signalling procedures. It influences organs that have low antioxidant defence, for example, the heart. Recent investigation demonstrated that mercury chloride $(0.02 \mathrm{mg} / \mathrm{kg} \mathrm{b.w}$ for 28 days) and lead nitrate ( $45 \mathrm{mg} / \mathrm{kg}$ b.w for 28 days) intoxication caused ROS production which incited histopathological changes in rat heart (Kalender, 2016).

\section{Lithium}

Lithium (Li) is a most widely used and studied long term treatment for the effective of bipolar treatment, used against both manic episode, depression and reduces the chance of committing suicide. Lithium has some clinical involvement as a narrow therapeutic index requiring routine observation of serum levels; however it is still regularly used in spite of various side effects. The most well-known alteration appears in the kidney, endocrine organs, gastrointestinal tract and in the heart. When Li is administered in low dose, electrocardiographic changes in patients accepting Li treatment have been reported. Li treatment is related with variable electrocardiography (ECG) changes including QT prolongation, ST section and $\mathrm{T}$ wave changes, heart arrhythmias, trio-ventricular disturbance and myocardial localized necrosis (MI). Likewise, lithium constricts cardiovascular sympathetic 
re-innervation after MI and Reactive Oxygen Species (ROS) are exceeding in ventricular remodelling following MI. Study demonstrated that Li (2, 5, or $100 \mathrm{mg}$ of lithium chloride/kg, i.p.) aggravated an expanded oxidative stress status, proven by high lipoperoxidation and protein carbonylation, with a low non protein thiols level and influenced antioxidant enzymes as CAT, Gpx and SOD (Mezni et al., 2017).

\section{Penconazole}

Triazole fungicides are one of the most important group of pesticides used in agriculture. The mechanism of action behind these fungicides is to inhibit the activity of lanosterol $14 \alpha$ demethylase (CYP51), which is a key enzyme for biosynthesis of ergosterol in fungi, leading to dysfunction of membrane and inhibits the uptake of substrate. Penconazole (PEN) (1- $(2,4$ dichloro- $\beta$ propylphenethyl)-1 H-1,2,4-triazole) is known as the active material of a systemic triazole fungicide basically used in horticultural, agricultural, and forestry industries for harmful pathogen control. This fungicide has shown a resistant toward degradation and also gets accumulated in soils. Penconazole induced cardioprotection in rats demonstrated that PEN (67 mg/kg, i.p. for 7 days) induced a state of oxidative stress in the heart of adult rats as proved by the increased lipid peroxidation, PCO formation, and the changed enzymatic and nonenzymatic antioxidant situation. PEN administration also resulted in inhibition of the cardiac AChE activity and altering the metabolism of lipid. The toxic effects of PEN are basically mediated through free radical generation, leading to injury in various cardiomyocyte structure (Chaâbane et al., 2016).

\section{Tilmicosin (TIL)}

This is a semi-synthetic macrolide antibiotic mostly used in veterinary medicine. It is a 16 -member macrolide which is obtained by chemical modification of desmycosin. This mechanism behind this antibiotic is to bind on the 50S ribosomal subunit thus inhibiting microbial protein synthesis. However, this drug has been reported to have cardiovascular toxicity in animals. The overdose administration causes positive chronotropic and negative inotropic cardiovascular dysfunction with increased heart rate and loss of ventricular function, specially in young animals. The above effect mainly depends on dose, animal species and route of administration. Tilmicosin when administered in rats $(75 \mathrm{mg} / \mathrm{kg}$, s.c.) induced cardiac injury reported by increase of AST, LDH, CK and cTnT biomarkers as well as myocardial tissue injury and myocytolysis (Fahmy et al., 2013). The administration of Tilmicosin results in causing various degree of lipid peroxidation, inhibition in antioxidant enzymes activities and changes in serum biochemical parameters of mice (Ibrahim, Abdel-Daim, 2015). Summary of chemicals

TABLE II - Summary of chemicals inducing myocardial infarction along with their mechanism

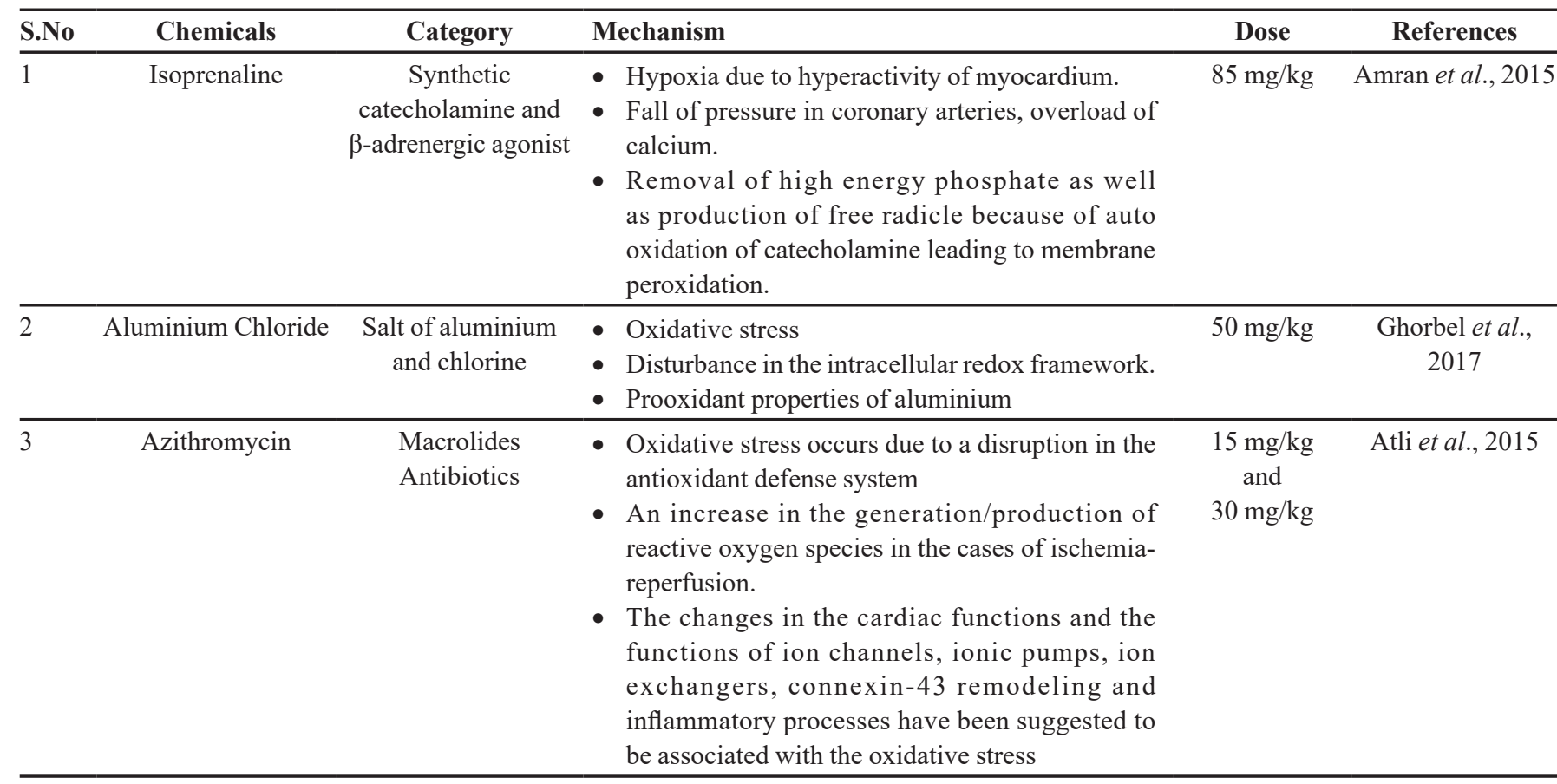


TABLE II - Summary of chemicals inducing myocardial infarction along with their mechanism (cont.)

\begin{tabular}{|c|c|c|c|c|c|}
\hline S.No & Chemicals & Category & Mechanism & Dose & References \\
\hline 4 & Bupivacaine & $\begin{array}{l}\text { Long-acting local } \\
\text { anaesthetic }\end{array}$ & $\begin{array}{l}\text { - Bupivacaine reduces the availability of fatty acids } \\
\text { for } \beta \text {-oxidation in myocardial mitochondria by } \\
\text { specific inhibition of the enzyme systems involved } \\
\text { in the carnitine shuttle. } \\
\text { - The resulting loss of energy substrate potentially } \\
\text { could contribute to the cardiotoxicity observed } \\
\text { clinically. } \\
\text { - Conduction blockade by inhibiting Na channel and } \\
\text { negative inotropy. }\end{array}$ & $6 \mu \mathrm{g} / \mathrm{mL}$ & $\begin{array}{c}\text { Křikava et al., } \\
2010\end{array}$ \\
\hline 5 & Carbon tetrachloride & $\begin{array}{c}\text { Clear, colourless, } \\
\text { volatile, heavy and } \\
\text { nonflammable liquid }\end{array}$ & $\begin{array}{l}\text { - Production of free radicals which is a rate limiting } \\
\text { process in cellular peroxidative damage, causing } \\
\text { oxidative stress, which produces the major } \\
\text { interrelated changes in cellular metabolism, thus } \\
\text { increasing the level of calcium inside the cell. } \\
\text { - Causes damage to the permeability and transport } \\
\text { of ions through membrane and also destroy the cell } \\
\text { by lipid peroxidation. }\end{array}$ & $1 \mathrm{~mL} / \mathrm{kg}$ & $\begin{array}{l}\text { Eshaghi et al., } \\
2012\end{array}$ \\
\hline 6 & Chlorpyrifos & $\begin{array}{c}\text { Broad spectrum } \\
\text { organophosphate } \\
\text { insecticide }\end{array}$ & $\begin{array}{l}\text { - Chlorpyrifos has multiple effects on cells including } \\
\text { generation of reactive oxygen species and } \\
\text { induction of intracellular oxidative stress thereby } \\
\text { disrupting normal cellular development and } \\
\text { differentiation of cell. }\end{array}$ & $5.4 \mathrm{mg} / \mathrm{kg}$ & $\begin{array}{c}\text { Baş, Kalender, } \\
2011\end{array}$ \\
\hline 7 & Cisplatin & $\begin{array}{c}\text { Organometallic } \\
\text { chemotherapeutic } \\
\text { drug }\end{array}$ & $\begin{array}{l}\text { - Cisplatin reacts with DNA, and causes intra and } \\
\text { inter crosslinkage. The subsequent DNA produced } \\
\text { starts apoptosis. } \\
\text { - It induces oxidative stress }\end{array}$ & $7.5 \mathrm{mg} / \mathrm{kg}$ & $\begin{array}{c}\text { Oguzturk et al., } \\
2016\end{array}$ \\
\hline 10 & Doxorubicin & $\begin{array}{c}\text { Anthracycline } \\
\text { category anti-cancer } \\
\text { drug }\end{array}$ & $\begin{array}{l}\text { Doxorubicin causes myocardial injury by means } \\
\text { of the development of free oxygen radicals. } \\
\text { - Oxidative injury to membrane lipids and other } \\
\text { cellular component, injury to the microtubules, } \\
\text { vacuolization, and sarcomere disturbance occurs } \\
\text { in myoctes. }\end{array}$ & $\begin{array}{c}1 \mathrm{mg} / \mathrm{kg} \\
2.5 \mathrm{mg} / \mathrm{kg}\end{array}$ & $\begin{array}{c}\text { Shahzadi et al., } \\
2014\end{array}$ \\
\hline 11 & Gamma Radiation & $\begin{array}{l}\text { Very short } \\
\text { wavelength } \\
\text { electromagnetic } \\
\text { radiation }\end{array}$ & $\begin{array}{l}\text { Biological frameworks of the body to deliver } \\
\text { free radicals or reactive oxygen species (ROS), } \\
\text { which causes injury to different cellular segment } \\
\text { including DNA, proteins and membrane lipids, } \\
\text { prompting chronic cellular injury. }\end{array}$ & $\begin{array}{l}10 \mathrm{~Gy} \\
\text { delivered at } \\
\text { a dose rate of } \\
0.46 \mathrm{~Gy} / \mathrm{min} \text {. }\end{array}$ & $\begin{array}{l}\text { Elkady, Mohamed, } \\
2016\end{array}$ \\
\hline
\end{tabular}


TABLE II - Summary of chemicals inducing myocardial infarction along with their mechanism (cont.)

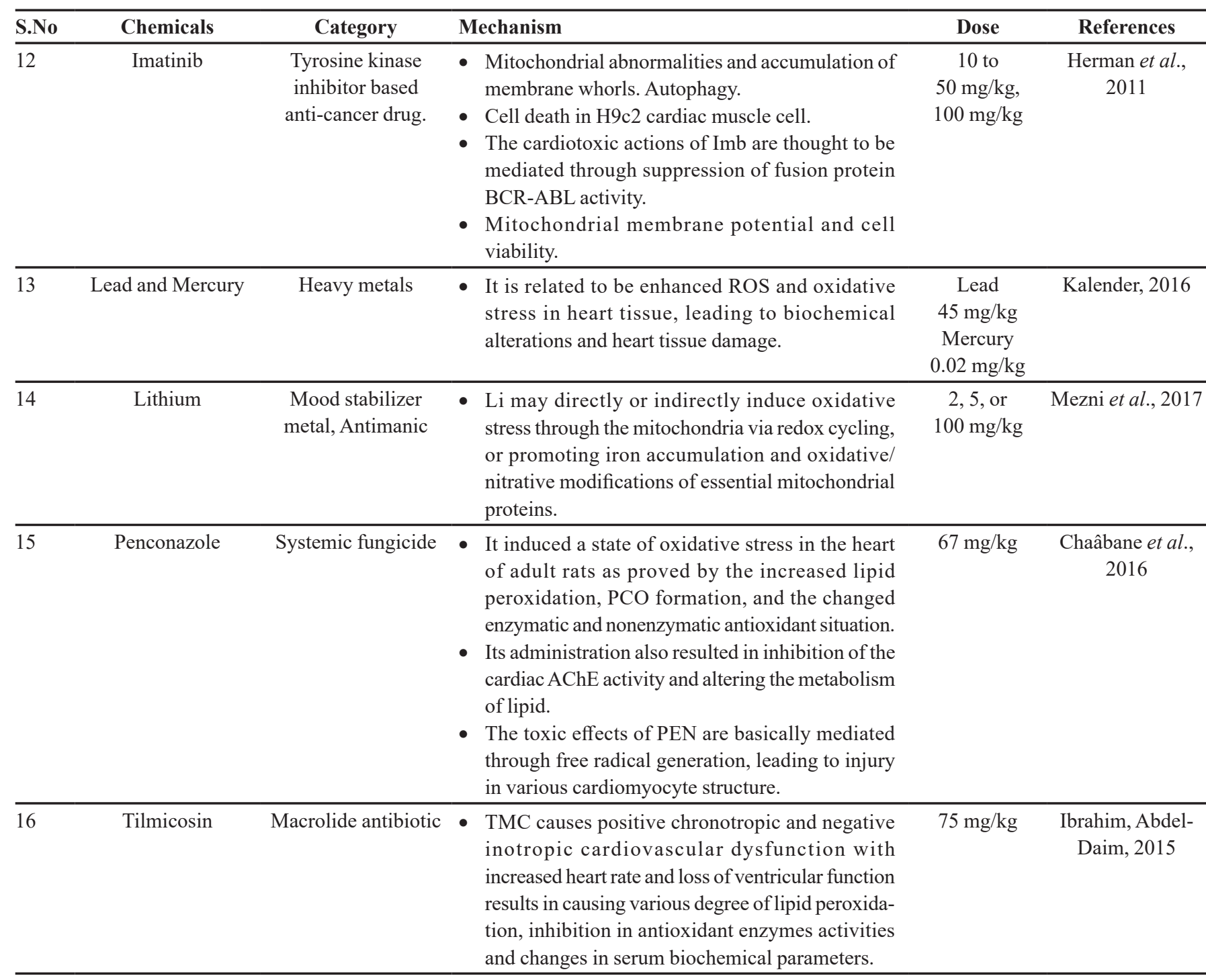

causing myocardial infarction along with their mechanism has been mentioned (Table II).

\section{DISCUSSION}

As a result of the epidemiological and financial factor of CHD-related MI extensive endeavours to reduce this illness are required. Since the comprehension of exact mechanism of disease is fundamental necessities to create proficient treatments the utilization of animal models is vital. In any case, each animal model has preferences and particular impediments and none of them is reasonable to ponder all parts of CHD-related MI. Before, an expansive number of studies have been performed in animals with unmistakable clinical heart problem to assess pathophysiology from the level of the unblemished instrumented animals to the tissue homogenate. These sorts of studies expedited a ton of data hemodynamic, neurohumoral enactment, myocardial capacity and subcellular and sub-atomic changes in the fizzling heart.

In relation to the previously mentioned animal models, it is evident that every animal model assumes a critical part in better comprehension of ischemic heart disease. The most recent couple of decades have seen generous headway in the treatment of ischemic heart illnesses because of expanding information of the molecular mechanism required amid ischemia/reperfusion damage. The major difference between heart size and unpredictability amongst laboratory animal and people confine the immediate interpretation of the trial results to the clinics. Model and species properties decide the attributes of the disorder. A helpful model ought to in 
any event be of technical significance, in this manner permitting potential therapeutic evaluation. Nonetheless, none of the accessible models precisely reiterates the unpredictable and dynamic pathology that describes human MI.

In any case, it is excessively straightforward, making it impossible to contend that the absence of dependable models for preclinical testing undermines examinations in clinical trials. A specific and accurate model ought to be picked in the wake of viewing the question to be replied. Better clinical MI stratification and distinguishing proof of activating natural factors will additionally build the interest for specific models. The requirement for accurate model stages and for the advancement of focused therapeutic mediations will develop with our insight on MI etiology and stratification.

Small animal models are generally utilized as a part of cardiovascular research due to their numerous points of interest over large animal models. They have a short life expectancy, enabling the researcher to take after the characteristic history of the disease at a rapid pace. Large animal models are the nearest models of human ailment yet they are not reasonable for high output studies. For result designed for clinical interpretation, it is basic that underlying outcomes from rat thinks about be affirmed in a large animal models as they more closely resembles the human heart. While picking a large animal model, we have to think about the anatomical and physiological contrasts between species.

Additionally, the improvement of genetically modified models takes into account quick foundation of verification of-principle that can later be investigated out into bigger animal models. Notwithstanding, rodents have a couple of disadvantages too. They are phylogenetically quite dissimilar from human and some patho-physiological highlights of diseases and their reaction to pharmacological medications may not be dependable indicators for humans. Now a days, transgenic animal models of hypertrophy and myocardial infarction are basically essential for understanding the molecular modifications behind the development of the disease. Addition or substitution of genes in transgenic mice together with scaled down physiological methods to assess the subsequent cardiovascular phenotypes permit the distinguishing proof of qualities that are causative for heart diseases and to assess molecular mechanism in charge of the improvement and movement of the disease.

Notwithstanding, we should recollect that these various animal models are a long way from resembling to coronary illness in people. Most models include the counterfeit reproduction of disease in those tissues which were earlier healthy, which varies enormously from the intricate and dynamic improvement of human cardiovascular sickness. Huge degrees of disparity in animal species, contrast to human life structures, small heart size and heart estimate and the trouble to extrapolate the discoveries to clinical settings are prime bottleneck of creature models that keep the pharmacological mediations from being incorporated into the general public. In the meantime, it is likewise critical to underline the significance of the refinement, decrease and substitution in animal research. At last animal models hold incredible significance in investigating novel mechanism, discoveries of new mediations, both pharmacological and surgical which can be clinically translated in human.

\section{CONCLUSION}

In view of the epidemiological and financial status of patient CHD-related HF a great determination to fight against this disorder are required. Currently, the most commonly used animal in myocardial models are the rat and mouse. The mouse specifically has the positive side of offering various transgenic and genetically-focused strains. However, large animal models have the benefit of a high level of physiological similarities to human and the less and can be easily applied in the complex technical changes. As the cardiovascular disorder has a complex nature, no animal model or species can be used to exactly reproduce the same disorder as that of human; in this manner, proper animal model selection is required which has maximum simulation toward the human disease. Apart from human similarity, certain other points are to be considered: contemplations of cost, framework and the necessity for specialized hand. Bringing these points into account, scientist must choose the model that best imitates the part of disease being examined. In specific, while moving from bottom to top it is important to test methods in that yield profoundly reproducible outcomes, yet in spite of these impediments, a proper strategies should be made in order to reduce the chances of error in results, and animal models remain the best apparatuses for identifying the effect of various molecules/ drugs in various myocardial diseases.

\section{ACKNOWLEDGMENT}

Author sincerely pays his heartfelt respect and gratitude toward Prof. Syed Waseem Akhtar, Hon. Chancellor and Prof. M.K.J Siddiqui, Hon. Vice Chancellor, Integral University for providing an excellent research environment. The University has 
provided a manuscript communication number for further communication (IU/R\&D/2018-000348).

\section{CONFLICT OF INTEREST}

There is no conflict of interest among the authors.

\section{REFERENCES}

Abdel-Wahab BA, Metwally ME. Clozapine-induced cardiotoxicity in rats: Involvement of tumour necrosis factor alpha, NF- $\kappa \beta$ and caspase-3. Toxicol Reports. 2014;1:1213-23.

Adaramoye O. Comparative effects of vitamin E and kolaviron (a biflavonoid from Garcinia kola) on carbon tetrachlorideinduced renal oxidative damage in mice. Pakistan J Biol Sci. 2009;12(16):1146-51.

Adler N, Camin LL, Shulkin P. Rat model for acute myocardial infarction: application to technetium-labeled glucoheptonate, tetracycline, and polyphosphate. J Nucl Med. 1976;17(3):203-7.

Alexander JM, Bruneau BG. Lessons for cardiac regeneration and repair through development. Trends Mol Med. 2010;16(9):42634.

Van Amerongen MJ, Harmsen MC, Petersen AH, Popa ER, Van Luyn MJA. Cryoinjury: a model of myocardial regeneration. Cardiovasc Pathol. 2008;17(1):23-31.

Amran AZ, Jantan I, Dianita R, Buang F. Protective effects of the standardized extract of Zingiber officinale on myocardium against isoproterenol-induced biochemical and histopathological alterations in rats. Pharm Biol. 2015;53(12):1795-802.

Atli O, Ilgin S, Altuntas H, Burukoglu D. Evaluation of azithromycin induced cardiotoxicity in rats. Int J Clin Exp Med. 2015;8(3):3681-90.

Azab KS, Bashandy M, Salem M, Ahmed O, Tawfik Z, Helal $\mathrm{H}$. Royal jelly modulates oxidative stress and tissue injury in gamma irradiated male Wister Albino rats. N Am J Med Sci. 2011;3(6):268-76.

Baş H, Kalender Y. Chlorpyrifos induced cardiotoxicity in rats and the protective role of quercetin and catechin. Gazi Univ $\mathbf{J}$ Sci. 2011;24(3):385-95.

Bentzon JF, Falk E. Atherosclerotic lesions in mouse and man: Is it the same disease? Curr Opin Lipidol. 2010;21(5):434-40.
Chaâbane M, Tir M, Hamdi S, Boudawara O, Jamoussi $\mathrm{K}$, Boudawara $\mathrm{T}$, et al. Improvement of heart redox states contributes to the beneficial effects of selenium against penconazole-induced cardiotoxicity in adult rats. Biol Trace Elem Res. 2016;169(2):261-70.

Chandrasekera PC, Pippin JJ. The human subject: an integrative animal model for 21(st) century heart failure research. Am J Transl Res. 2015;7(9):1636-47.

Conci E, Pachinger O, Metzler B. Mouse models for myocardial ischaemia/reperfusion. J Für Kardiol J Cardiol. 2006;13(78):239-44.

Davie C, Pierre-Valentin J, Pollard C, Standen N, Mitcheson $\mathrm{J}$, Alexander P, et al. Comparative pharmacology of guinea pig cardiac myocyte and cloned hERG (IKr) channel. J Cardiovasc Electrophysiol. 2004;15(11):1302-9.

Elkady AA, Mohamed ET. Possible role of withania somnifera against gamma radiation induced cardiotoxicity in male albino rats. Pak J Zool. 2016;48(2):539-45.

Eshaghi M, Zare S, Banihabib N, Nejati V, Farokhi F, Mikaili P. Cardioprotective effect of cornus mas fruit extract against carbon tetrachloride induced-cardiotoxicity in albino rats. J Basic Appl Sci Res. 2012;2(11):11106-14.

Fadillioglu E, Oztas E, Erdogan H, Yagmurca M, Sogut S, Ucar M, et al. Protective effects of caffeic acid phenethyl ester on doxorubicin-induced cardiotoxicity in rats. J Appl Toxicol. 2004;24(1):47-52.

Fahmy M, Elazab A, Gomaa GM, Abdo W. Protective effect of s-methyl cysteine against tilmicosin-induced cardiotoxicity in rats. Pak Vet J. 2014;34(3):253-8318.

Feldman AM, Weinberg EO, Ray PE, Lorell BH. Selective changes in cardiac gene expression during compensated hypertrophy and the transition to cardiac decompensation in rats with chronic aortic banding. Circ Res. 1993;73(1):184-92.

Gado AM, Nasser A, Adam I, Aldahmash BA. Cardiotoxicity induced by cyclophosphamide in rats: Protective effect of curcumin. J Res Environ Sci Toxicol. 2013;2(4):2315-5698.

Gao E, Lei YH, Shang X, Huang ZM, Zuo L, Boucher M, et al. A Novel and efficient model of coronary artery ligation and myocardial infarction in the mouse. Cir Res. 2011;107(12):144553. 
Gengo PJ, Sabbah HN, Steffen RP, Sharpe JK, Kono T, Stein $\mathrm{PD}$, et al. Myocardial beta adrenoceptor and voltage sensitive calcium channel changes in a canine model of chronic heart failure. J Mol Cell Cardiol. 1992;24(11):1361-9.

Ghorbel I, Elwej A, Chaabane M, Jamoussi K, Zeghal N. Protective effect of selenium against aluminium chloride induced cardiotoxicity in rats. Pharm Biomed Res. 2017;3(2):19-25.

Grisel P, Meinhardt A, Lehr HA, Kappenberger L, Barrandon Y, Vassalli G. The MRL mouse repairs both cryogenic and ischemic myocardial infarcts with scar. Cardiovasc Pathol. 2008;17(1):14-22.

Halapas A, Papalois A, Stauropoulou A, Philippou A, Pissimissis $\mathrm{N}$, Chatzigeorgiou A, et al. In vivo models for heart failure research. In Vivo. 2008;22(6):767-80.

Harada K, Grossman W, Friedman M, Edelman ER, Prasad P $\mathrm{V}$, Keighley CS, et al. Basic fibroblast growth factor improves myocardial function in chronically ischemic porcine hearts949. J Clin Invest. 1994;94(2):623-30.

Hasenfuss G. Animal models of human cardiovascular disease, heart failure and hypertrophy. Cardiovasc Res. 1998;39(1):6076.

Hasty AH, Shimano H, Osuga JI, Namatame I, Takahashi A, Yahagi N, et al. Severe hypercholesterolemia, hypertriglyceridemia, and atherosclerosis in mice lacking both leptin and the low density lipoprotein receptor. J Biol Chem. 2001;276(40):37402-8.

Herman EH, Knapton A, Rosen E, Thompson K, Rosenzweig $\mathrm{B}$, Estis J, et al. A multifaceted evaluation of imatinib-induced cardiotoxicity in the rat. Toxicol Pathol. 2011;39(7):1091-106.

Hernando V, Inserte J, Sartório CL, Parra VM, Poncelas-Nozal M, Garcia-Dorado D. Calpain translocation and activation as pharmacological targets during myocardial ischemia/ reperfusion. J Mol Cell Cardiol. 2010;49(2):271-9.

Hofker MH, van Vlijmen BJ, Havekes LM. Transgenic mouse models to study the role of APOE in hyperlipidemia and atherosclerosis. Atherosclerosis. 1998;137(1):1-11.

Holtz JR, Studer H, Reinecke H, Just HD. Modulation of myocardial sarcoplasmic reticulum $\mathrm{Ca}^{++}$-ATPase in cardiac hypertrophy by angiotensin converting enzyme? Basic Res Cardiol. 1992;87:191-204.
Hood WB, McCarthy B, Lown B. Myocardial infarction following coronary ligation in dogs. Hemodynamic effects of isoproterenol and acetylstrophanthidin. Circ Res. 1967;21(2):191-9.

Van Der Hoorn JWA, Jukema JW, Havekes LM, Lundholm E, Camejo G, Rensen PCN, et al. The dual PPAR $\alpha / \gamma$ agonist tesaglitazar blocks progression of pre-existing atherosclerosis in APOE*3Leiden.CETP transgenic mice. Br J Pharmacol. 2009;156(7):1067-75.

Hu W, Polinsky P, Sadoun E, Rosenfeld ME, Schwartz SM. Atherosclerotic lesions in the common coronary arteries of ApoE knockout mice. Cardiovasc Pathol. 2005;14(3):120-5.

Ibrahim A, Abdel-Daim M. Modulating effects of spirulina platensis against tilmicosin-induced cardiotoxic-ity in mice. Cell J. 2015;17(1):137-144.

Igić R. The isolated perfused "working” rat heart: A new method. J Pharmacol Toxicol Methods. 1996;35(2):63-7.

Iwanaga K, Takano H, Ohtsuka M, Hasegawa H, Zou Y, Qin $\mathrm{Y}$, et al. Effects of G-CSF on cardiac remodeling after acute myocardial infarction in swine. Biochem Biophys Res Commun. 2004;325(4):1353-9.

Lee KT, Jarmolych J, Kim DN, Grant C, Krasney JA, Thomas WA, Bruno AM. Production of advanced coronary atherosclerosis, myocardial infarction and "sudden death" in swine. Exp Mol Pathol. 1971;15(2):170-90.

Kalender S. Effects of mercury chloride and lead nitrate induced cardiotoxicity in male rats. J Harran Univ Med Fac. 2016;13:136-43.

Klocke R, Tian W, Kuhlmann MT, Nikol S. Surgical animal models of heart failure related to coronary heart disease. Cardiovasc Res. 2007;74(1):29-38.

Křikava I, Jarkovský J, Štourač P, Nováková M, Ševčík P. The effects of lidocaine on bupivacaine-induced cardiotoxicity in the isolated rat heart. Physiol Res. 2010;59(Suppl 1):S65-9.

Kumar M, Kasala ER, Bodduluru LN, Dahiya V, Sharma D, Kumar V, et al. Animal models of myocardial infarction: Mainstay in clinical translation. Regul Toxicol Pharmacol. 2016;76:221-30.

de Leiris J, Harding DP, Pestre S. The isolated perfused rat heart: A model for studying myocardial hypoxia or ischaemia. Basic Res Cardiol. 1984;79(3):313-21. 
Leppänen P, Luoma JS, Hofker MH, Havekes LM, Ylä-Herttuala S. Characterization of atherosclerotic lesions in apo E3-leiden transgenic mice. Atherosclerosis. 1998;136(1):147-52.

Li AC, Brown KK, Silvestre MJ, Willson TM, Palinski W, Glass CK. Peroxisome proliferator-activated receptor gamma ligands inhibit development of atherosclerosis in LDL receptor-deficient mice. J Clin Invest. 2000;106(4):523-31.

Lian Y, Gao L, Guo P, Zhao Y, Lin T. Grape seed proanthocyanidins extract prevents cisplatin-induced cardiotoxicity in rats. Food Sci Technol Res. 2016;22(3):403-8.

Linz W, Scholkens BA, Manwen J, Wilhelm M GD. The heart as a target for converting enzyme-inhibitors-studies in ischemic isolated working rat hearts. J Hypertens. 1986;4:S477-9.

Lipp. Cardiotoxicity of cytotoxic drugs. Anticancer drug toxicity. Prevention, management and clinical pharmacokinetics. New York: Marcel Dekker; 1991.

Liu YH, Yang XP, Nass O, Sabbah HN, Peterson E, Carretero OA. Chronic heart failure induced by coronary artery ligation in Lewis inbred rats. Am J Physiol. 1997;272(2 Pt 2):H722-7.

Martorana PA, Linz W, Göbel H, Petry P, Schölkens BA. Effects of nicainoprol on reperfusion arrhythmia in the isolated working rat heart and on ischemia and reperfusion arrhythmia and myocardial infarct size in the anesthetized rat. Eur J Pharmacol. 1987;143(3):391-401.

Mezni A, Aoua H, Khazri O, Limam F, Aouani E. Lithium induced oxidative damage and inflammation in the rat's heart: Protective effect of grape seed and skin extract. Biomed Pharmacother. 2017;95:1103-11.

Michael LH, Entman ML, Hartley CJ, Youker KA, Zhu J, Hall SR, et al. Myocardial ischemia and reperfusion: a murine model. Am J Physiol. 1995;269(6 Pt 2):H2147-54.

Miller DL, Van Winkle DM. Ischemic preconditioning limits infarct size following regional ischemia-reperfusion in in situ mouse hearts. Cardiovasc Res. 1999;42(3):680-4.

Murry CE, Jennings RB, Reimer KA. Preconditioning with ischemia : injury delay of lethal cell ischemic myocardium. Circulation. 1986;74(5):1224-1136.

Murry CE, Kay MA, Bartosek T, Hauschka SD, Schwartz SM. Muscle differentiation during repair of myocardial necrosis in rats via gene transfer with MyoD. J Clin Invest. 1996;98:2209-17.
Oguzturk H, Ciftci O, Cetin A, Kaya K, Disli OM, Turtay MG. Beneficial effects of hesperidin following cis diamminedichloroplatinum - induced damage in heart of rats. Niger J Clin Pract. 2016;19(1):99-103.

Oliveira MG, Passos LC, Santos Júnior EG, Barbosa AC, Santos DB. Use of an indicator to evaluate physician adherence to prescription guidelines for the treatment of heart failure. Braz J Pharm Sci. 2013;49(4):831-836.

Páez MT, Catalina Rodríguez D, López DF, Castañeda JA, Buitrago DM, Cuca LE, et al. Croton schiedeanus Schltd prevents experimental hypertension in rats induced by nitric oxide deficit. Braz J Pharm Sci. 2013;49(4):865-871.

Partownavid P, Sharma S, Rahman S, Eghbali M. Intralipid rescue of bupivacaine-induced cardiotoxicity in rats is abolished by glibenclamide, an ATP potassium channel blocker. Circulation. 2013;128.

Pfeffer MA, Pfeffer JM, Fishbein MC, Fletcher PJ, Spadaro J, Kloner RA, et al. Myocardial infarct size and ventricular function in rats. Circ Res. 1979;44(4):503-12.

Plump AS, Smith JD, Hayek T, Aalto-Setälä K, Walsh A, Verstuyft JG, et al. Severe hypercholesterolemia and atherosclerosis in apolipoprotein E-deficient mice created by homologous recombination in ES cells. Cell. 1992;71(2):34353.

Reeve JLV, Duffy AM, O'Brien T, Samali A. Don't lose heart - therapeutic value of apoptosis prevention in the treatment of cardiovascular disease. J Cell Mol Med. 2005;9(3):609-22.

Reffelmann T, Sensebat O, Birnbaum Y, Stroemer E, Hanrath P, Uretsky BF, et al. A novel minimal-invasive model of chronic myocardial infarction in swine. Coron Artery Dis. 2004;15(1):712.

Robey TE, Murry CE. Absence of regeneration in the MRL/ $\mathrm{MpJ}$ mouse heart following infarction or cryoinjury. Cardiovasc Pathol. 2008;17(1):6-13.

Rona G, Kahn DS. Experimental studies on the healing of cardiac necrosis. Ann N Y Acad Sci. 1969;156:177-88.

Roos KP, Brady AJ. Individual sarcomere length determination from isolated cardiac cells using high-resolution optical microscopy and digital image processing. Biophys J. 1982;40(3):233-44. 
Roth DM, White FC, Mathieu-Costello O, Guth BD, Heusch G, Bloor CM, et al. Effects of left circumflex Ameroid constrictor placement on adrenergic innervation of myocardium. Am J Physiol. 1987;253(6 Pt 2):H1425-34.

Sabbah HN, Stein PD, Kono T, Gheorghiade M, Levine TB, Jafri S, et al. A canine model of chronic heart failure produced by multiple sequential coronary microembolizations. Am J Physiol. 1991;260(4 Pt 2):H1379-84.

Sanan DA, Newland DL, Tao R, Marcovina S, Wang J, Mooser $\mathrm{V}$, et al. Low density lipoprotein receptor-negative mice expressing human apolipoprotein B-100 develop complex atherosclerotic lesions on a chow diet: no accentuation by apolipoprotein(a). Proc Natl Acad Sci. 1998;95(8):4544-9.

Schimmel KJM, Richel DJ, van den Brink RBA, Guchelaar HJ. Cardiotoxicity of cytotoxic drugs. Cancer Treat Rev. 2004;30(2):181-91.

Scholz W, Albus U, Lang HJ, Linz W, Martorana PA, Englert $\mathrm{HC}$, et al. Hoe 694, a new $\mathrm{Na}+/ \mathrm{H}+$ exchange inhibitor and its effects in cardiac ischaemia. Br J Pharmacol. 1993;109(2):562-8.

Scholz W, Albus U, Linz W, Martorana P, Lang HJ, Schölkens BA. Effects of $\mathrm{Na}+/ \mathrm{H}+$ exchange inhibitors in cardiac ischemia. J Mol Cell Cardiol. 1992;24(7):731-9.

Shahzadi A, Sonmez I, Allahverdi O, Onal B, Kandaz C, Ozyazgan SO, et al. Cardiac Troponin-I (cTnI) a biomarker of cardiac injuries induced by doxorubicin alone and in combination with ciprofloxacin, following acute and chronic dose protocol in sprague dawley rats. Int $\mathrm{J}$ Pharmacol. 2014;10(5):258-66.

Srikanth G, Prakash P, Tripathy N, Dikshit M, Nityanand S. Establishment of a rat model of myocardial infarction with a high survival rate: A suitable model for evaluation of efficacy of stem cell therapy. J Stem Cells Regen Med. 2009;5(1):30-6.

St Louis JD, Hughes GC, Kypson AP, DeGrado TR, Donovan CL, Coleman RE, et al. An experimental model of chronic myocardial hibernation. Ann Thorac Surg. 2000;69(5):1351-7.

Thomas NP, Johns BJO. Experimental myocardial infarction: I. A method of coronary occlusion in small animals. Ann Surg. 1954;140(5):675-82.

Uttam Paul SG. Study of cardioprotective activity of normovedic in $\mathrm{Ccl} 4$ induced cardiotoxicity in rats. Int J Pharma Bio Sci. 2016;7(3):135-43.
Vandervelde S, Van Amerongen MJ, Tio RA, Petersen AH, Van Luyn MJA, Harmsen MC. Increased inflammatory response and neovascularization in reperfused vs. nonreperfused murine myocardial infarction. Cardiovasc Pathol. 2006;15(2):83-90.

Véniant MM, Zlot CH, Walzem RL, Pierotti V, Driscoll R, Dichek D, et al. Lipoprotein clearance mechanisms in LDL receptor-deficient "apo-B48- only" and "apo-B100-only" mice. J Clin Invest. 1998;102(8):1559-68.

Verdouw PD, van den Doel MA, de Zeeuw S, Duncker DJ. Animal models in the study of myocardial ischaemia and ischaemic syndromes. Cardiovasc Res. 1998;39(1):121-35.

Viswanatha Swamy AHM, Patel UM, Koti BC, Gadad PC, Patel NL, Thippeswamy AHM. Cardioprotective effect of Saraca indica against cyclophosphamide induced cardiotoxicity in rats: a biochemical, electrocardiographic and histopathological study. Indian J Pharmacol. 2013;45(1):44-8.

Vleeming W, Van Der Wouw PA, Van Rooij HH, Wemer J. In vitro method for measurement of cardiac performance and responses to lnotropic drugs after experimentally induced myocardial infarction in the rat. J Pharmacol Methods. 1989;21:95-102.

Vogel H, editor. Drug discovery and evaluation: pharmacological assays. Springer Science \& Business Media; 2007.

Yu JZ, Rodrigues B, McNeill JH. Intracellular calcium levels are unchanged in the diabetic heart. Cardiovasc Res. 1997;34(1):918 .

Zadelaar S, Kleemann R, Verschuren L, De Vries-Van Der Weij J, Van Der Hoorn J, Princen HM, et al. Mouse models for atherosclerosis and pharmaceutical modifiers. Arterioscler Thromb Vasc Biol. 2007;27(8):1706-21.

Zaragoza C, Gomez-Guerrero C, Martin-Ventura JL, Blanco-Colio L, Lavin B, Mallavia B, et al. Animal models of cardiovascular diseases. J Biomed Biotechnol. 2011;2011:497841.

Received for publication on $21^{\text {st }}$ May 2018 Accepted for publication on $10^{\text {th }}$ July 2018 